Progress in Photovoltaics:

Research and Applications

\title{
Impact of individual atmospheric parameters on CPV system power, energy yield and cost of energy
}

\begin{tabular}{|r|l|}
\hline Journal: & Progress in Photovoltaics: Research and Applications \\
\hline Manuscript ID: & PIP-12-201.R1 \\
\hline Wiley - Manuscript type: & Research Article \\
\hline Date Submitted by the Author: & n/a \\
\hline Keywords: List of Authors: & $\begin{array}{l}\text { Chan, Ngai Lam Alvin; Imperial College London, Department of Physics } \\
\text { Brindley, Helen; Imperial College London, Department of Physics } \\
\text { Ekins-Daukes, Nicholas John; Imperial College London, U.K., Physics }\end{array}$ \\
\hline & $\begin{array}{l}\text { concentrator photovoltaics, atmospheric parameters, air mass, aerosols, } \\
\text { impact, energy yield }\end{array}$ \\
\hline &
\end{tabular}

\section{SCHOLARONE ${ }^{\text {w }}$}

Manuscripts 


\title{
Impact of individual atmospheric parameters on CPV system power, energy yield and cost of energy
}

\author{
N.L.A. Chan*, H.E. Brindley, N.J. Ekins-Daukes \\ Department of Physics, Imperial College London, South Kensington, SW7 2BZ, U.K.
}

*Corresponding author. Email: ngai.chan@imperial.ac.uk, Telephone: +44 (0) 2075946682

The performance of concentrator photovoltaic systems can be characterized by the power output under reference conditions and the output energy yield under realistic solar illumination. For a range of locations, the frequency distribution of individual atmospheric parameters and their quantitative impact on power output of a concentrator photovoltaic system has been evaluated, with aerosols shown to have a substantial impact on performance at many sites. Limited knowledge of atmospheric parameters results in a difference of up to $75 \%$ in simulated energy yield over an annual period, and up to $75 \%$ deviation in the expected levelized cost of energy.

\section{INTRODUCTION}

Multi-junction solar cells have become standard components in high efficiency concentrator photovoltaic (CPV) systems, offering excellent potential for low-cost solar electricity generation [1,2]. The performance of such systems is rated under a reference solar spectrum [3] and standardized ambient environmental conditions, allowing for ease of comparison between modules of different sizes and system designs.

Under realistic operating conditions however, system performance deviates from reference values in a complex manner We have identified two critical issues when considering CPV performance - the impact of individual atmospheric parameters on the rated power, and the influence of atmospheric data knowledge on energy yields.

\subsection{Review of published atmospheric parameters impact methods}

The concept of quantifying the effect of atmospheric parameters on system performance has focused on calculating the spectral mismatch via the use of a daily spectral enhancement factor (DSEF) [4]. Whilst a useful technique, this considers only the short-circuit current available, and does not calculate the expected output power.

A different approach examined the "spectrometric characterization" of a double-junction solar cell with measured quantum efficiencies, where the effective irradiance received by each junction is translated into a "spectral parameter" that is itself related to electrical characteristics of the cell or module in question $[5,6]$. Such methods compress all the complexity of the atmosphere into a single dimensionless parameter, and a large number of measurements are required to achieve a reasonable degree of accuracy.

\subsection{Review of published energy yield prediction methods}

Efforts have been made towards predicting the power generated by both flat-plate and concentrator photovoltaic systems as a function of relevant measurements - a short summary for CPV is provided below:

1. Linear regression methods $[5,7,8]-$ a concentrator photovoltaic system is deployed and the power output and relevant atmospheric parameters are measured over a sufficiently long observation period. A linear regression relationship is then calculated numerically and power output is given as a function of other parameters. An example from [7] for a multivariate relationship is given in Eq. 1:

$$
P=a_{1} D N I+a_{2}(D N I)^{2}+a_{3} A M+a_{4} P W
$$


where $\mathrm{P}$ is the module power output, direct normal irradiance (DNI) represents the amount of sunlight incident on the system, air mass (AM) and precipitable water (PW) represent atmospheric parameters believed to have an impact on system performance. Coefficients for these relationships $\left(a_{1}, a_{2} \ldots\right)$ are found by performing regression analysis, and are noted to vary substantially between locations with different atmospheric conditions. We have investigated the validity of the method highlighted in Equation 1 using a measured dataset for Toyohashi, Japan that has been discussed in a separate publication [9] and found that when coefficients generated for southwestern US conditions are applied to a calculation for the module sited in Japan, the modelled yield differs from the measured yield by $9.6 \%$. Further details are given in the appendix.

2. Translational approaches $[10,11]$ - the system characteristics under reference conditions are translated to realistic conditions encountered by the module during deployment. Data including the current-voltage curve, direct normal irradiance and module temperature are all measured with appropriate instrumentation at reference conditions. The concentrator module does not need to be situated at the final deployment location to obtain estimates of power output.

3. Utilization factor methods $[12,13]$ - by defining the ratio of measured and modelled short circuit currents, this method attempts to capture the influence of the spectrum and temperature on energy yield. Similar to the multivariate regression method described in Equation 1, a large number of measurements are required to obtain good accuracy.

4. Typical Meteorological Year (TMY) [14]- using "typical" values for atmospheric parameters with hourly resolution, the direct solar spectrum can be simulated using radiative transfer codes. A cell model can then be used to compute the power output over a long period of time with good time resolution. TMY datasets are publicly available for most areas of the continental United States [15] and parts of the Negev Desert [16], and can also be generated by commercial data providers for locations around the world.

\subsection{Our approach}

Previously, the impact of various atmospheric parameters has been characterised as the difference in efficiency resulting from extreme values of individual parameters [9], which confirmed that of the atmospheric parameters investigated, air mass, aerosol optical depth and precipitable water have the greatest impact on system efficiency within realistic value ranges. Other atmospheric constituents such as ozone and other trace gases, such as nitrogen dioxide and sulphur dioxide, had negligible impact on CPV efficiency.

An alternative approach is used in this paper. By examining historically measured values of fundamental atmospheric parameters, we consider their impact on CPV system performance, taking the frequency distributions into account. The impact of each parameter on module power output is computed for three distinct locations.

We have simulated the power output of a CPV system previously deployed at Toyohashi, Japan, using a validated model [9] with a temporal resolution of 15 minutes, over entire annual periods, resulting in electrical energy yields. Varying levels of knowledge about the atmospheric parameters has been modelled; the most basic level of knowledge is when only the date, time and location are known, hence allowing an estimate of the air mass; in the most detailed simulations all relevant available atmospheric parameters are used. We demonstrate the availability of atmospheric data has a substantial impact on energy production and generation costs for many locations where CPV can expect deployment.

\section{SIMULATED CPV SYSTEM}


Starting from basic semiconductor parameters and applying carrier transport equations and appropriate radiative transfer codes, we have developed the Syracuse computer model [17] simulating the performance of a CPV module from fundamental physical principles.

The performance of a module composed of 20 triple junction $\mathrm{InGaP} / \mathrm{In}_{0.01} \mathrm{GaAs} / \mathrm{Ge}$ solar cells connected in series, illuminated by 550X solar concentration via a shaped Fresnel lens has been simulated in this publication. Simulated quantum efficiencies and current-voltage characteristics of the module under AM1.5D reference conditions are given in Figure 1 and 2 respectively, whilst the atmospheric parameters used to generate the reference spectrum are shown in Table 1. The module is based on the best available knowledge of a real concentrator system sited in Toyohashi, Japan. The model has been described in detail and the simulations have been experimentally verified in other publications [17-19], leading to agreement in energy yields of within $2 \%$. By running multiple simulations at a range of parameter values, it has been possible to extract the system response to individual parameters - here we focus on the electrical power output.

It is important to note that the cell examined here is top-junction limited under reference conditions, and is known to overproduce current in the bottom Germanium junction, with consequences for cell response to certain atmospheric parameters. We anticipate the module response to vary substantially for cells with different bandgaps.

\section{ATMOSPHERIC PARAMETERS AND SYSTEM RESPONSE}

We focus on direct normal irradiance (DNI) in this discussion, and investigate the effect of each atmospheric parameter on both DNI and module power output. A brief summary of the relevant physics and an examination of each parameter are given below. Further details can be found in [20].

As solar radiation passes through the atmosphere, its transmission can be described by the Beer Lambert Law [20], $I_{\lambda}=I_{0 \lambda} e^{-A M \tau_{\lambda}}$, where $I_{0}$ is the extraterrestrial irradiance, $I$ is the irradiance incident on the photovoltaic system, $A M$ is the optical air mass and $\tau$ is the total optical depth of the atmosphere. The subscript $\lambda$ indicates the dependence on wavelength of the relevant quantities. Over the wavelength range considered here the total optical depth of the atmosphere will consist of contributions from molecular scattering (so called Rayleigh scatter), aerosol, water vapour and other trace gases such as ozone. Explicitly accounting for the effects of the various extinction processes on the atmospheric optical depth, the Beer Lambert Law becomes:

$$
I_{\lambda}=I_{0 \lambda} e^{-A M\left(\tau_{R \lambda}+\tau_{A \lambda}+\tau_{W \lambda}+\tau_{G \lambda}\right)}
$$

where $\tau_{R}, \tau_{A}, \tau_{W}, \tau_{G}$ are the optical depths associated with molecular scattering, aerosol, water vapour and other trace gases respectively and each of these quantities is a function of wavelength, $\lambda$.

In our radiative transfer modelling, we make use of the Simple Model of the Atmospheric Radiative Transfer of Sunshine (SMARTS, v2.9.5) [21], to simulate both spectral and broadband DNI. SMARTS considers separate optical masses for each of these extinction processes [20], and we use the relationship given in [21] to calculate the optical air mass as:

$$
A M=\left[\cos \left(\theta_{0}\right)+a_{1} \theta_{0}^{a_{2}}\left(a_{3}-\theta_{0}\right)^{a_{4}}\right]^{-1} \quad \text { - Eq. } 3
$$

where $\theta_{0}$ is the solar zenith angle in radians, $a_{1}=4.5665 \times 10^{-1}, a_{2}=0.07, a_{3}=96.4836$ and $a_{4}$ $=-1.6970$.

An air mass of $1(A M=1)$ implies the Sun is directly overhead, with a solar zenith angle of zero and typical atmospheric path length of $\sim 100 \mathrm{~km}$.

The air mass, aerosol and precipitable water data have been obtained from the Aerosol Robotic Network (AERONET) [22, 23], a federation of ground-based remote sensing aerosol 
networks with standardized instruments, calibration and processing. As such, the data used has undergone a cloud screening process [24]. As CPV systems only accept the direct component of total solar irradiance, the use of cloud-screened data provides a reasonable method of characterizing CPV performance in the deployment locations.

In this publication, we use data from on AERONET sites in geographical areas of high CPV potential: Rogers Dry Lake, USA (R); Tamanrasset, Algeria (T); Sede Boqer, Israel (SB); Solar Village, Saudi Arabia (SV); and Jaipur, India (J). Locations are indicated in Figure 3, whilst the years selected and estimated cloudless solar yields are given in Table 2. A full annual cycle for each site has been assessed and is broadly representative, as we demonstrate later in this section.

Our baseline spectrum is the ASTM G-173 reference [3] and the parameter values used to generate it are shown in Table 1 . The cell temperature has been maintained at $25^{\circ} \mathrm{C}$, or $298 \mathrm{~K}$, in line with standard test conditions (STC) in order to isolate the effects of the solar spectrum. It is known that this will vary in realistic deployment conditions.

\subsection{Air mass}

The attenuation of DNI in pristine atmospheres is primarily attributable to molecular scattering and has a $\lambda^{-4}$ dependence. The amount of attenuation depends strongly on pathlength, represented by air mass, and is strongly attenuating at short wavelengths. Measurements of the solar zenith angle are made at AERONET sites, and Equation 3 is invoked to calculate air mass. This is primarily a function of time of day and the planetary tilt.

For the locations examined, the air mass distributions show negligible differences, due to their similar latitudes. In Figure 4 we present a distribution for all locations encompassing the years indicated. A plot of simulated module power against air mass is shown in Figure 5.

\subsection{Aerosols}

Aerosols absorb and scatter at a wide range of wavelengths, and have been identified in previous publications $[25,26]$ as an important factor in CPV system performance. As expressed in Equation 2, their influence on the solar irradiance can be characterized by the aerosol optical depth $\tau_{\mathrm{A}}(\mathrm{AOD})$, the vertical integral of the extinction coefficient (absorption plus scattering) due to aerosol over the full atmospheric depth.

To obtain the most accurate assessment of the impact of aerosols on the solar spectrum, the ideal case would be to measure and model the AOD explicitly at every wavelength. In the SMARTS radiative transfer code, AOD is expressed at one standard wavelength of $500 \mathrm{~nm}$, abbreviated as $A O D_{500}$. To capture the wavelength dependence of $A O D$ at other wavelengths, the model uses the extinction Angström Exponent, derived from the Angström Relation [27-29], given in Equation 4, where $\lambda$ is given in microns. In general, the smaller the extinction Angström Exponent, the larger the aerosol particles, and vice versa. Large aerosol particles are usually associated with sea-salt and mineral dust, particularly relevant along coastlines and in deserts, whilst small aerosol particles are indicative of urban pollutants and biomass combustion [30].

$$
\tau_{\lambda 1} \lambda_{1}^{-\alpha}=\tau_{\lambda 2} \lambda_{2}^{-\alpha}
$$

We use AERONET measurements to supply the inputs required by the SMARTS code. AERONET sites provide AODs at a select number of wavelengths (generally including 440 , 675,870 and $1020 \mathrm{~nm}$ ). We derive $\mathrm{AOD}_{500}$ from these measurements using equations 5 and 6 , making use of the measurements that bracket the required wavelength. In our discussion of the impact of Angström Exponent on cell performance we frame our results in terms of the value calculated using AODs measured at 440 and $870 \mathrm{~nm}, \alpha_{440-870}$ (Equation 7), in order to provide a degree of consistency with products that are routinely available from the AERONET website. 
Other publications [32] have examined the yearly mean values of turbidity (expressed as aerosol optical depth at $1000 \mathrm{~nm}$ ) at a wide range of locations, which is related via the Angström Exponent to $A O D_{500}$. Though this is a useful first step, $A_{O} D_{500}$, can vary substantially from the average. Here, long-term data has been examined for the locations identified in Figure 3 - a frequency distribution of $A O D_{500}$ values for each site is given in Figure 6 alongside the simulated power response of the module to changing $A O D_{500}$ in Figure 7.

In the majority of locations, $\mathrm{AOD}_{500}$ values much larger than the reference value, indicated by the grey vertical line, are common. As expected, the shapes of the AOD distributions are essentially log-normal, with the distribution of values at Rogers Dry Lake showing significantly lower levels of aerosol loading compared to the other sites highlighted here.

Using a similar approach to examine the Angström Exponent for the same locations, the normalised frequency distributions of $\alpha_{440-870}$ are presented in Figure 8 . Clear differences again exist between locations, for example at Tamanrasset and Solar Village where one would expect the predominant aerosol type to be dust the Angstrom Exponent values are small, whereas at Rogers Dry Lake and Jaipur, high Angström Exponent values indicate the majority of particles are of a small size, typically associated with soot and agricultural byproducts [33].

In Figure 9, module power is simulated as a function of Angstrom Exponent, with AOD maintained at the reference value - in this case, module power does not change greatly as AOD is low. The effect of changes in Angström Exponent will be amplified at higher AOD values, as seen in Figure 10.

We find the distribution for $\mathrm{AOD}_{500}$ and Angström Exponent can change slightly on an interannual basis as seen in Figure 11 and 12. Given the significant impact on cell performance of $\mathrm{AOD}_{500}$ in particular, this highlights the need for long-term observations of spectral aerosol optical depth, and/or the ability to accurately predict these data. However, for this initial study, one set of annual data at each location can give an insight into the impact of aerosols on CPV system response.

\subsection{Precipitable Water}

Water vapour has absorption bands in both the visible and near-infrared parts of the solar spectrum, relevant to multi junction solar cell performance. Precipitable water is the depth of 
water vapour that would be precipitated out at a given location from the full atmospheric column above the location.

In Figure 13, the distribution of measured precipitable water values are given for the same locations discussed in previous sections, alongside the module power response to changing precipitable water in Figure 14. Most of the locations considered here are desert-like and correspondingly exhibit a skewed distribution consistent with dry conditions. Tamanrasset is situated at an altitude of $1385 \mathrm{~m}$, so measurements made here are above the lowest kilometer or so of atmosphere where the highest concentrations of water vapour (and potentially dust aerosol) would be expected. Jaipur has a large range of precipitable water values, with the highest values recorded in the period from July to September and coinciding with the Indian summer monsoon [34].

No significant inter-annual differences in the PW frequency distribution for Sede Boqer, Solar Village and Rogers Dry Lake are seen, as demonstrated in Figure 15.

\section{QUANTIFYING THE IMPACT OF ATMOSPHERIC PARAMETERS ON CPV POWER}

The influence of atmospheric parameters has previously been defined as the difference in module efficiency between the most extreme parameter values recorded over the test period [26]. Drawing on each parameter's long-term normalised frequency distribution from Section 3 and taking into account the likelihood of each value occurring, it is possible to calculate the impact on power, $\Delta \mathrm{P}$, due to each parameter or set of parameters. The proposed methodology can be applied in any location to modules and cells of any size and design, provided sufficient data is available.

We find strong correlation between AOD and Angström Exponent, and thus they are considered together, with further details on their 2-dimensional frequency distribution available in the appendix. The expected impact on power for air mass $\left(\Delta P_{A M}\right)$, precipitable water $\left(\Delta P_{P W}\right)$ and aerosols $\left(\Delta P_{\text {Aerosols }}\right)$ is given in mathematical form in Equations 8-10.

$$
\begin{array}{cc}
\Delta P_{A M}=\sum_{n}\left[P_{A M 1.5 D}-P_{A M}(n)\right] \times f_{A M}(n) & \text { - Eq. } 8 \\
\Delta P_{P W}=\sum_{n}^{n}\left[P_{A M 1.5 D}-P_{P W}(n)\right] \times f_{A M}(n) & \text { - Eq. } 9 \\
\Delta P_{\text {Aerosols }}=\sum_{m} \sum_{n}\left[P_{A M 1.5 D}-P_{A O D, \text { Angstrom }}(m, n)\right] \times f_{A O D, \text { Angstrom }}(m, n) & \text { - Eq. } 10
\end{array}
$$

where $P_{A M 1.5 D}$ represents module power under the AM1.5D reference spectrum illumination, $P_{A M}(n), P_{P W}(n), P_{A O D, A n g s t r o m}(m, n)$ represent the module power at parameter value $\boldsymbol{n}$ (in the case of aerosols, parameter values $\boldsymbol{m}$ and $\boldsymbol{n}) . \quad f(n)$ and $f(m, n)$ represent the normalized frequency distribution associated with parameter value $\boldsymbol{n}$ ( $\boldsymbol{m}$ and $\boldsymbol{n}$ in the aerosols case).

By varying the values of one parameter and calculating electrical power output of the system using the Syracuse simulation model, whilst at the same time keeping other parameters constant at AM1.5D reference values, the system response's to a single parameter can be calculated, providing the $\left[P_{A M 1.5 D}-P_{A M}(n)\right],\left[P_{A M 1.5 D}-P_{P W}(n)\right]$ and $\left[P_{A M 1.5 D}-P_{A O D, \text { Angstrom }}(m, n)\right]$ terms.

To obtain the expected change in power from each parameter, Equations 8-10 are applied to each value of $\boldsymbol{n}$ (or $\boldsymbol{m}$ and $\boldsymbol{n}$, in the case of aerosols), multiplying the normalized frequency with power deviation. This is performed individually for air mass, aerosols and PW. 
Since AOD and Angström Exponent are strongly correlated, a two-dimensional frequency distribution is required. It must be stressed that such a tool is far more useful when used to consider the relative importance of certain atmospheric parameters on a CPV module, rather than determining the exact power output. For that, detailed simulations as discussed in Section 5 are essential.

In Table 3 we show the calculated impact of each parameter on device power at the previously highlighted locations. Only in one location is air mass revealed to be the parameter with the largest impact - Rogers Dry Lake, California, USA. In all other locations, the impact of aerosols is larger than air mass, whilst the impact of PW is small for this particular system at these locations for the cell under consideration. In [9], PW was shown to have a non-trivial impact on module efficiency, this result is still consistent, but a different metric (module power output) is examined here.

Such results suggest that the variability in aerosol loading and characteristics can only be neglected in certain areas, such as the southwestern United States. In the other locations studied here, aerosols must be accounted for if accurate estimates of performance are to be made.

In addition, aerosols and precipitable water have been examined separately here.

Precipitable water is seen to have little impact on power, due to the presence of a Germanium bottom junction that overproduces current in comparison to the top and middle junctions. In devices that are more current-matched, for example where the Germanium bottom junction in the standard triple junction device is replaced with a higher bandgap material, PW is expected to have a greater impact. Absorption in the relevant bands will decrease the available current to the bottom junction, amplifying the impact of precipitable water. In those situations, any covariance between PW and aerosols due to the uptake of water will add complexity and must be accounted for.

\section{SIMULATED ENERGY YIELDS - DATA DENIAL}

For the best estimates of energy yields from a CPV system at a particular location, a timeresolved set of simulations using all available atmospheric parameters should offer the highest accuracy. In some geographical locations, there may be very few sites measuring these parameters, or none at all. It is instructive to consider the potential errors that may arise, given various levels of knowledge regarding the atmosphere. Although satellite retrievals of atmospheric parameters can be used to supplement direct in-situ and ground based measurements orbital constraints mean that they are not always available at the desired timescales or locations. In addition, the inversion process, coupled with differences in the area being sampled can result in significant differences when the products are evaluated against direct measurements [35].

We have used cloudless AERONET data to obtain information on air mass, aerosols and precipitable water. Simulations are performed at the same time as AERONET measurements, ensuring cloudy conditions are filtered out.

\section{1 - Module power output simulation methodology}

Over annual periods, we simulated the system performance for the module described in Section 2 using the Syracuse computer program. I-V characteristics are output for each simulation point and the maximum power point is found, with trapezoidal integration invoked to obtain an estimate of the energy yield. As before, the temperature is maintained at $298 \mathrm{~K}$ $\left(25^{\circ} \mathrm{C}\right)$ for all simulations, in order to isolate the effect of the solar spectrum on system output.

AERONET measurements are made approximately every 15 minutes given the air mass is less than 7. We have calculated that for Sede Boqer in 2006, it would have been possible for AERONET to make measurements for $98.0 \%$ of the DNI delivered. Similarly, for Tamaransset in 2007 and Solar Village in 2001, the equivalent figures are $97.6 \%$ and $98.6 \%$ respectively, indicating AERONET measurements are representative of a large proportion of 
the energy delivered. At higher air mass, horizon shading from mountains and structures may also affect any measurements.

Data collected is subject to a quality assurance process and a cloud filter, which examines the variation in the calculated aerosol optical depths [24]. Beyond a certain variation threshold, the measurement is treated as cloudy, leading to gaps in the cloudless data.

We simulate system performance whenever an AOD measurement is made, making the assumption that data gaps of 30 minutes or longer are due to cloudy conditions, not instrument error or downtime, and make no effort to include them in our calculation of the energy output. A schematic of the integration method is given in Figure 16.

Although we have no measured system output to compare against at these locations, past experience $[9,18]$ indicates that given the correct DNI and spectral distribution, system behaviour can be reproduced to an appropriate degree of accuracy, where the annual energy yield is within $2 \%$ of measured values.

The number of atmospheric parameters used in the simulation has been varied to investigate the effect of data denial on energy yield. At the lowest detail level, only air mass is known, and all other parameters are set to default AM1.5D conditions. Progressively more atmospheric parameters are added, until air mass, precipitable water, $A O D_{500}$ and $\alpha_{440-870}$ are all included in the highest detail simulation.

\section{2 - DNI Validation}

First, we compared measured DNI data with model estimates generated by SMARTS 2.9 .5 at Tamanrasset and Sede Boqer. Observations were taken from the Baseline Surface Radiation Network (BSRN) [36] over a range of atmospheric conditions. From the results, we have confidence that during cloudless periods, the modelled and actual broadband DNI are in good agreement. Examples of the measured and simulated broadband DNI on select days are given in Figures 17-20, where sudden dips in the measured irradiance are attributable to cloud cover. Red crosses indicate simulations where only the air mass is varied from reference conditions. Blue stars indicate simulations where all available atmospheric knowledge is used. DNI clearly varies substantially depending on atmospheric knowledge, particularly during periods with high aerosol loading.

\section{3 - Simulation Results}

With this methodology, we examined our set of candidate CPV locations. By examining the module power output for the most basic and complex cases over the single days considered in Figures 21-24, clear differences in power exist depending on the atmospheric parameters included.

When examined over annual periods, such variations become apparent in the estimated cloudless electrical energy yields, listed in Table 4, with the percentage deviation from the best effort simulation in brackets. A graphical representation of the estimated annual electrical energy yields at different detail levels is given in Figure 25 . Up to $75 \%$ deviation in energy yield can be noted between the most basic and complex simulations. In most locations, the difference is substantial - indicating a need to correctly capture the atmospheric state should any realistic estimates of energy yield need to be made.

Notably, at Rogers Dry Lake, the differences are much smaller, and knowledge of additional atmospheric parameters has no significant impact on the energy yield. Amonix CPV systems have shown agreement between measured and simulated energy yields of within $1 \%$ can be achieved in this geographical area [37], and we observe this within our simulations. This is to be expected as the AM1.5D reference conditions were selected to be representative of the southwestern United States, the geographical region of Rogers Dry Lake. The frequency distribution for $\mathrm{AOD}_{500}$ shows a strong skew towards lower values - which from Figure 7 we would expect to result in a low impact on power for this system. In addition, as the average 
values for each parameter are close to the AM1.5D values, the availability of additional parameters does not result in large differences in the energy yield calculations.

At Jaipur, we note a dramatic difference of $\sim 75 \%$ in energy yield between the basic and most detailed simulations, due principally to higher $\mathrm{AOD}_{500}$ values. The Angstrom Exponent, related to aerosol size, is also shown to have a significant impact on energy yields. This highlights a need to consider all relevant atmospheric parameters if future CPV deployment in locations with significant and variable aerosol loading, such as the Indian subcontinent, is to be successful. It is however apparent that the energy yield at Jaipur is substantially lower than other locations in all cases, due to more frequent cloud cover at the site.

Jaipur has been identified as a site with high DNI potential $[38,39]$ and is the site of many bids for the deployment of up to 500MW of photovoltaic systems under the Jawaharlal Nehru National Solar Mission [40], an initiative from the Government of India. Given these factors, CPV deployment has been considered as a possibility in the region.

Further, we note that specifically for this solar cell structure, knowledge of precipitable water only has a small impact on the energy yield of this particular system, but the added knowledge of aerosol has a large effect, in agreement with our calculations in Section 4.

\section{IMPACT ON COST OF ENERGY}

By examining the impact of atmospheric parameters on CPV systems and examining their relative importance, investors will be able to make informed decisions as to which measurements are required to accurately predict CPV system performance at a particular location. The suitability of a system to a certain location can be assessed, assuming no drastic and sudden changes in atmospheric conditions.

For any energy system, the metric of concern to investors and consumers is the cost of the energy produced. Levelized Cost of Energy (LCOE) is a widely accepted concept describing the cost at which energy must be sold to break-even over the technology's lifetime, in both flat-plate and concentrator photovoltaics [41-43]. We present a simplified version in Equation 11, adapted from [42], to illustrate the need to consider atmospheric parameters in modeling when calculating energy production costs for CPV systems.

$$
L C O E=\frac{\text { Lifecycle Cost }}{\text { Lifetime Energy Generation }}=\frac{P C+\sum_{n=1}^{N} \frac{A O}{(1+D R)^{n}}}{\sum_{n=1}^{N} \frac{E_{\text {initial }}(1-S D R)^{n}}{(1+D R)^{n}}} \quad \text { - Eq. } 11
$$

In this formalism, PC represents the project cost, $\mathrm{DR}$ is the discount rate, $\mathrm{AO}$ is the annual operation and maintenance cost, SDR is the system yield degradation rate, and $\mathrm{N}$ is the number of years of system operation. We have assumed the project cost is paid in full at the start of the project, and have made no assumptions regarding the value of the system after 30 years. Values used in this calculation are given in Table 5, and are based on estimates made in other publications regarding commercially viable photovoltaic power plants [42, 44, 45]. The installed cost is our best estimate for the present installations, but this is expected to decrease as the technology matures. The energy yields used are taken from Table 4, and we assume electrical power generated in North Africa is, in this case, exported to Europe, similar to the DESERTEC concept [46]. The resulting LCOE values are shown in Table 6 for different levels of atmospheric knowledge. Higher system power output naturally leads to lower LCOE, with the lowest generation costs associated with Rogers Dry Lake. It is imperative, however, to consider the attractiveness of CPV in relation to other energy sources. The average LCOE for each technology in the United States, Europe and India have been derived from publications by the International Energy Agency [47] and the World Bank [48], and are compared to the estimated LCOE for CPV systems, depending on the amount of atmospheric data used in the simulation. Figures $26-28$ indicate CPV can be cost 
competitive with both coal and gas in the United States regardless of atmospheric parameters availability and given the assumptions listed, but its competitiveness will change substantially in Europe and India depending on the simulation detail level. It is noteworthy that at Jaipur, $\mathrm{CPV}$ is much more competitive than off-grid diesel generation in all cases.

Having assumed that the cost for the system remains the same regardless of deployment location, we note the predicted energy generation term changes depending on the level of knowledge regarding atmospheric conditions, the difference in LCOE between the most basic (only air mass is known) and complex (air mass, aerosols and precipitable water are known) cases can be expressed in the following fashion:

$$
\triangle L C O E=\frac{L C O E_{A M}-L C O E_{A M, P W, A O D, A E}}{L C O E_{A M, P W, A O D, A E}} * 100
$$

For the years examined, in some locations $\triangle \mathrm{LCOE}$ can be up to $+75 \%$, leading to substantially higher LCOE when more atmospheric information is incorporated - this is particularly important for locations with highly variable aerosol loading such as Jaipur, India. Little deviation in LCOE is seen for Rogers Dry Lake as expected, given its similarity to reference conditions.

\section{CONCLUSIONS}

We have developed an approach to quantify the impact of individual atmospheric parameters on the performance of CPV systems based on physical phenomena. We have shown that in addition to air mass, aerosols can have a large impact on the performance of this system at many sites considered suitable for CPV. In many locations, it has been demonstrated that key atmospheric parameters must be considered for accurate energy yield estimates. Precipitable water is noted to have little impact on module power and energy yield for this particular triple-junction, but this is expected to change when other designs with better current-matching are considered.

The frequency distributions of air mass, aerosol optical depth, Angström Exponent and precipitable water have been calculated for several locations across the globe, showing substantial variation from the AM1.5D reference conditions.

Cloudless-sky simulations using atmospheric data from AERONET measurements with high temporal resolution were performed for several sites over annual periods. The simulated energy yield can vary by up to $75 \%$ between the most complex case where all available parameters are used, and the most basic simulation, where only air mass and the location is known. Notably, at Rogers Dry Lake in the southwestern US, the differences are small, and can be attributed to the similarity between the atmospheric parameters at this site and the AM1.5D reference conditions.

Further, we show the difference in energy yields between the most basic and complex cases can increase the levelized cost of energy by up to $25 \%$ for many locations with high solar irradiance. Locations with complex atmospheric conditions, such as Jaipur, show a difference of up $75 \%$ in LCOE depending on the atmospheric parameters available for energy yield modelling.

\section{ACKNOWLEDGEMENTS}

We thank Jeannette van den Bosch, Emilio Cuevas-Agullo, Arnon Karnieli, Naif Al-Abbadi, Brent Holben and S.N. Tripathi and their staff for establishing and maintaining the AERONET sites used in this investigation. The authors would like to acknowledge the Baseline Surface Radiation Network and its staff at the Sede Boqer and Tamanrasset sites for establishing and maintaining the sites used in this publication. NLAC gratefully acknowledges a PhD studentship from the Grantham Institute for Climate Change. 
This work has been supported by the European Commission and NEDO through the funding of the project NGCPV EUROPE-JAPAN (EU Ref. N: 283798).

\section{REFERENCES}

1. Swanson, R.M., The promise of concentrators. Progress in Photovoltaics: Research and Applications, 2000. 8(1): p. 93-111.

2. Kurtz, S., Opportunities and Challenges for Development of a Mature Concentrating Photovoltaic Power Industry, 2010.

3. Emery, K., D. Myers, and S. Kurtz. What is the appropriate reference spectrum for characterizing concentrator cells? in 29th IEEE Photovoltaic Specialists Conference. 2002.

4. Gueymard, C.A. Daily spectral effects on concentrating PV solar cells as affected by realistic aerosol optical depth and other atmospheric conditions. in Proc. SPIE 7410, 741007. 2009. San Diego, CA, USA.

5. Peharz, G., G. Siefer, and A.W. Bett, A simple method for quantifying spectral impacts on multi-junction solar cells. Solar Energy, 2009. 83(9): p. 1588-1598.

6. Meusel, M., R. Adelhelm, F. Dimroth, A.W. Bett, and W. Warta, Spectral mismatch correction and spectrometric characterization of monolithic III-V multi-junction solar cells. Progress in Photovoltaics: Research and Applications, 2002. 10(4): p. 243-255.

7. Muller, M. Minimizing Variation in Outdoor CPV Power Ratings. in CPV-7. 2011. Las Vegas.

8. Marion, B., Preliminary Investigation of Methods for Correcting for Variations in Solar Spectrum under Clear Skies, 2010, National Renewable Energy Laboratory.

9. Chan, N., T.B. Young, H. Brindley, N. Ekins-Daukes, K. Araki, Y. Kemmoku, and M. Yamaguchi, Validation of energy prediction method for a concentrator photovoltaic module in Toyohashi Japan. Progress in Photovoltaics: Research and Applications, 2012.

10. Cameron, C., C. Crawford, J. Foresi, D. King, R. McConnell, D. Riley, A. Sahm, and J. Stein, Performance Model Assessment for Multi-Junction Concentrating Photovoltaic Systems. AIP Conference Proceedings, 2010. 1277(1): p. 290-293.

11. Rubio, F., M. Martinez, J. Perea, D. Sanchez, and P. Banda. Comparison of the different CPV rating procedures: Real measurements in ISFOC. in Photovoltaic Specialists Conference (PVSC), 2009 34th IEEE. 2009.

12. Gerstmaier, T., S. van Riesen, A. Gombert, A. Mermoud, T. Lejeune, and E. Duminil, Software Modeling of FLATCON CPV Systems. AIP Conference Proceedings, 2010. 1277(1): p. 183-186.

13. Mermoud, A., Technico-economical Optimization of Photovoltaic Pumping Systems Pedagogic and Simulation Tool Implementation in the PVsyst Software, 2006, Research report of the Institut of the Environnemental Sciences, University of Geneva.

14. Kinsey, G.S., A. Nayak, L. Mingguo, and V. Garboushian, Increasing Power and Energy in Amonix CPV Solar Power Plants. Photovoltaics, IEEE Journal of, 2011. 1(2): p. 213-218.

15. Database, N.S.R. 1991- 2005 Update: Typical Meteorological Year 3.

16. Faiman, D., Data Processing for the Negev Radiation Survey2007: State of Israel, Ministry of National Infrastructures, Research and Development Division.

17. Ekins-Daukes, N.J., T.R. Betts, Y. Kemmoku, K. Araki, H.S. Lee, R. Gottschalg, M.B. Boreland, D.G. Infield, and M. Yamaguchi. Syracuse - a multi-junction concentrator system computer model. in Photovoltaic Specialists Conference, 2005. Conference Record of the Thirty-first IEEE. 2005.

18. Ekins-Daukes, N., Y. Kemmoku, K. Araki, T.R. Betts, R. Gottschalg, D.G. Infield, and M. Yamaguchi. The Design Specification For Syracuse; A Multi-Junction Concentrator System Computer Model. in Proc. 19th European Photovoltaic Solar Energy Conference. 2004. Paris, France.

19. Lee, H.S., N.J. Ekins-Daukes, K. Araki, Y. Kemmoku, and M. Yamaguchi. Field test and analysis: the behavior of 3-J concentrator cells under the control of cell temperature. in Photovoltaic Specialists Conference, 2005. Conference Record of the Thirty-first IEEE. 2005. 
20. Liou, K.N., Radiation and cloud processes in the atmosphere: theory, observation and modeling 1992: Oxford University Press.

21. Gueymard, C.A., Parameterized transmittance model for direct beam and circumsolar spectral irradiance. Solar Energy, 2001. 71(5): p. 325-346.

22. Holben, B.N., T.F. Eck, I. Slutsker, D. TanrE, J.P. Buis, A. Setzer, E. Vermote, J.A. Reagan, Y.J. Kaufman, T. Nakajima, F. Lavenu, I. Jankowiak, and A. Smirnov, AERONET--A Federated Instrument Network and Data Archive for Aerosol Characterization. Remote Sensing of Environment, 1998. 66(1): p. 1-16.

23. Guirado, C., E. Cuevas, V. Cachorro, M. Mimouni, L. Zeudmi, C. Toledano, S. Alonso, S. Basart, L. Blarel, P. Goloub, and J.M. Baldasano. Preliminar characterization of columnar aerosols properties (AOD-AE) at the Saharan Tamanrasset (Algeria) station. in 37th Annual European Meeting on Atmospheric Studies by Optical Methods. 2010. University of Valladolid, Spain.

24. Smirnov, A., B.N. Holben, T.F. Eck, O. Dubovik, and I. Slutsker, Cloud-Screening and Quality Control Algorithms for the AERONET Database. Remote Sensing of Environment, 2000. 73(3): p. 337-349.

25. Kurtz, S.R., J.M. Olson, and P. Faine, The difference between standard and average efficiencies of multijunction compared with single-junction concentrator cells. Solar Cells, 1991. 30(1-4): p. 501-513.

26. Young, T.B., A. Chan, N.J. Ekins-Daukes, K. Araki, Y. Kemmoku, and M. Yamaguchi. Atmospheric Considerations when Estimating the Energy Yield from III-V Photovoltaic Solar Concentrator Systems. in 25th European Photovoltaic Solar Energy Conference and Exhibition / 5th World Conference on Photovoltaic Energy Conversion. 2010. Valencia, Spain.

27. Ångström, A., On the Atmospheric Transmission of Sun Radiation and on Dust in the Air. Geografiska Annaler, 1929. 11: p. 156-166.

28. Ångström, A., On the Atmospheric Transmission of Sun Radiation. II. Geografiska Annaler, 1930. 12: p. 130-159.

29. Ångström, A., Techniques of Determinig the Turbidity of the Atmosphere1. Tellus, 1961. 13(2): p. 214-223.

30. Russell, P.B., R.W. Bergstrom, Y. Shinozuka, A.D. Clarke, P.F. DeCarlo, J.L. Jimenez, J.M. Livingston, J. Redemann, O. Dubovik, and A. Strawa, Absorption Angstrom Exponent in AERONET and related data as an indicator of aerosol composition. Atmos. Chem. Phys., 2010. 10(3): p. 1155-1169.

31. Schuster, G.L., O. Dubovik, and B.N. Holben, Angstrom exponent and bimodal aerosol size distributions. J. Geophys. Res., 2006. 111(D7): p. D07207.

32. Gueymard, C., Latitude and Climate Dependent Optimal Siting and Spectral Effects of Concentrating PV Technologies: Preliminary Analysis, in CPV Workshop2007: Marburg.

33. Ramachandran, S., R. Rengarajan, A. Jayaraman, M.M. Sarin, and S.K. Das, Aerosol radiative forcing during clear, hazy, and foggy conditions over a continental polluted location in north India. J. Geophys. Res., 2006. 111(D20): p. D20214.

34. Jade, S., M.S.M. Vijayan, V.K. Gaur, T.P. Prabhu, and S.C. Sahu, Estimates of precipitable water vapour from GPS data over the Indian subcontinent. Journal of Atmospheric and Solar-Terrestrial Physics, 2005. 67(6): p. 623-635.

35. Chu, D.A., Y.J. Kaufman, C. Ichoku, L.A. Remer, D. TanrË, and B.N. Holben, Validation of MODIS aerosol optical depth retrieval over land. Geophys. Res. Lett., 2002. 29(12): p. 8007.

36. Ohmura, A., H. Gilgen, H. Hegner, G. Muller, M. Wild, E.G. Dutton, B. Forgan, C. Freunhlich, R. Philipona, A. Heimo, G. Koenig-Langlo, B. McArthur, R. Pinker, C.H. Whitlock, and K. Dehne, Baseline Surface Radiation Network (BSRN/WCRP): New Precision Radiometry for Climate Research. Bulletin of the American Meteorological Society, 1998. 79(10): p. 2115-2136.

37. Kinsey, G.S., K. Stone, J. Brown, and V. Garboushian, Energy prediction of Amonix CPV solar power plants. Progress in Photovoltaics: Research and Applications, 2011: p. n/a-n/a.

38. India Solar Resource Maps - National Renewable Energy Laboratory. [cited 2012; Available from: http://www.nrel.gov/international/ra india.html. 
39. Perez, R., J. Schlemmer, D. Renne, S. Cowlin, R. George, and B. Bandyopadhyay. Validation of the SUNY Satellite Model in a Meteosat Environment. in ASES Annual Conference. 2009. Buffalo, New York.

40. Jawaharlal Nehru National Solar Mission, Ministry of New and Renewable Energy, Government of India. 2010; Available from: http://india.gov.in/allimpfrms/alldocs/15657.pdf.

41. Nishikawa, W., S. Horne, and J. Melia. LCOE FOR CONCENTRATING PHOTOVOLTAICS (CPV). in International Conference on Solar Concentrators for the Generation of Electricity (ICSC - 5). 2008. Palm Desert, CA USA.

42. Darling, S.B., F. You, T. Veselka, and A. Velosa, Assumptions and the levelized cost of energy for photovoltaics. Energy \& Environmental Science, 2011. 4(9): p. 31333139.

43. Fraas, L. and L. Partain. 2nd ed. Solar Cells and Their Applications, ed. L. Fraas and L. Partain2010, Hoboken, N.J.: Wiley.

44. Faiman, D., D. Raviv, and R. Rosentreich. The triple sustainability of CPV within the framework of the Raviv model. in 20th European Photovoltaic Solar Energy Conference. 2005. Barcelona, Spain.

45. Branker, K., M.J.M. Pathak, and J.M. Pearce, A review of solar photovoltaic levelized cost of electricity. Renewable and Sustainable Energy Reviews, 2011. 15(9): p. 44704482.

46. Trieb, F. and H. Müller-Steinhagen, The DESERTEC Concept - Sustainable Electricity and Water for Europe, Middle East and North Africa, 2007.

47. International Energy Agency and OECD Nuclear Energy Agency, Projected Costs of Generating Electricity 2010 Edition, 2010.

48. Sargsyan, G., M. Bhatia, S.G. Banerjee, K. Raghunathan, and R. Soni, Unleashing the Potential of Renewable Energy in India, 2010, The World Bank.

\section{APPENDIX A}

Unfortunately no wind data was recorded on-site at Toyohashi, and as such the ASTM E2527 method was not implemented as a comparison.

We have made investigations into the validity of the method highlighted in Equation 1 when applied to locations outside of the southwest USA - we applied the model to our Toyohashi dataset of measured system data, where a wide range of atmospheric conditions was encountered $\left(0.027<\mathrm{AOD}_{500}<1.054,0.41<\mathrm{PW}<6.61 \mathrm{~cm}\right)$.

In the first test, all datapoints recorded throughout the year encompassing all atmospheric conditions are used to compute the coefficients $\mathrm{a}_{0}, \mathrm{a}_{1}, \mathrm{a}_{2}$ and $\mathrm{a}_{3}$ from multivariate regression, Equation 1 is then applied to estimate the energy yield, leading to good agreement within $0.0003 \%$ of the measured total energy production.

In the second test, the measurements made at Toyohashi were first filtered to only include atmospheric conditions encountered at Rogers Dry Lake $\left(0.0006<\mathrm{AOD}_{500}<0.397,0.09<\right.$ $\mathrm{PW}<2.85 \mathrm{~cm}$ ), and a separate set of coefficients was generated and used to estimate the energy yield. This tests whether coefficients obtained in the US test conditions can be accurate for predicting system performance in a different location. In this case, the NREL regression method underestimated the yield at Toyohashi by $9.6 \%$, highlighting the need for new coefficients each time a particular system is deployed at a particular location, one of the key restrictions of this method.

\section{APPENDIX B}

We have calculated 2-dimensional normalized frequency histograms (Figures 29-31) examining the covariance of aerosol optical depth at $500 \mathrm{~nm}$ and the Angstrom exponent, evaluated between 440 and $870 \mathrm{~nm}$, for Rogers Dry Lake, Sede Boqer and Jaipur for the simulation periods given in Table 2. Distinct differences can be noted for each site, particularly in Jaipur, where high Angstrom Exponents dominate, indicating smaller aerosol 
particles. Such variations serve to highlight the need to consider the covariance between aerosol optical depth and Angstrom Exponent carefully. 


\begin{tabular}{|l|l|}
\hline Atmospheric Parameter & Value \\
\hline Air mass & 1.5 \\
\hline Precipitable Water & $1.42 \mathrm{~cm}$ \\
\hline Aerosol Optical Depth, $500 \mathrm{~nm}$ & 0.084 \\
\hline Angstrom Exponent $<500 \mathrm{~nm}$ & 0.964 \\
\hline Angstrom Exponent $>500 \mathrm{~nm}$ & 1.431 \\
\hline
\end{tabular}

Table 1 -Atmospheric parameter values used to generate the ASTM G-173 AM1.5D reference spectrum [3].

\begin{tabular}{|c|c|c|}
\hline Location & Simulation period & $\begin{array}{c}\text { Modelled Cloudless Solar } \\
\text { Yield (kWh/m2/year) }\end{array}$ \\
\hline Rogers Dry Lake & $\begin{array}{c}2001-01-01 \text { to } \\
2002-01-01\end{array}$ & 1663.37 \\
\hline Tamanrasset & $\begin{array}{c}2007-01-01 \text { to } \\
2008-01-01\end{array}$ \\
\hline Sede Boqer & $\begin{array}{c}2006-01-01 \text { to } \\
2007-01-01\end{array}$ \\
\hline Solar Village & $2001-01-01$ to & 1424.50 \\
\hline Jaipur & $2002-01-01$ & 1636.05 \\
\hline $2011-09-01$ to & 772.57 \\
\hline
\end{tabular}

Table 2 - Simulation periods and modelled cloudless solar yields for the selected locations.

\begin{tabular}{|c|c|c|c|}
\hline Location & $\Delta \mathbf{P}_{\text {Air mass }}$ & $\Delta \mathbf{P}_{\text {Aerosols }}$ & $\Delta \mathbf{P}_{\text {Precipitable Water }}$ \\
\hline Tamanrasset & $-29.99 \mathrm{~W}$ & $-15.58 \mathrm{~W}$ & $0.77 \mathrm{~W}$ \\
\hline Solar Village & $-30.95 \mathrm{~W}$ & $-23.30 \mathrm{~W}$ & $0.42 \mathrm{~W}$ \\
\hline Sede Boqer & $-30.71 \mathrm{~W}$ & $-18.47 \mathrm{~W}$ & $0.34 \mathrm{~W}$ \\
\hline Rogers Dry Lake & $-30.80 \mathrm{~W}$ & $1.08 \mathrm{~W}$ & $0.56 \mathrm{~W}$ \\
\hline Jaipur & $-30.65 \mathrm{~W}$ & $-46.17 \mathrm{~W}$ & $0.04 \mathrm{~W}$ \\
\hline
\end{tabular}

Table 3 - Impact of air mass, precipitable water and aerosols on module power over an annual period, compared to calculations using the AM1.5D reference spectrum. In all locations except Rogers Dry Lake, aerosols are responsible for a substantial drop in rated power. Precipitable water causes little change in module power, due to the presence of an over-producing Ge junction.

\begin{tabular}{|c|c|c|c|c|c|}
\hline \multirow{2}{*}{$\begin{array}{l}\text { Detail } \\
\text { Level }\end{array}$} & \multicolumn{5}{|c|}{ Annual Energy Yields (kWh) } \\
\hline & $\begin{array}{l}\text { Rogers } \\
\text { Dry Lake }\end{array}$ & Tamanrasset & $\begin{array}{l}\text { Sede } \\
\text { Boqer }\end{array}$ & $\begin{array}{c}\text { Solar } \\
\text { Village }\end{array}$ & Jaipur \\
\hline $\begin{array}{c}\text { Air mass, } \\
\text { PW, } \\
\text { AOD }_{500,}, \\
\text { Angström } \\
\text { Exponent }\end{array}$ & $\begin{array}{c}237.55 \\
(-)\end{array}$ & $\begin{array}{c}201.18 \\
(-)\end{array}$ & $\begin{array}{c}180.40 \\
(-)\end{array}$ & $\begin{array}{c}202.93 \\
(-)\end{array}$ & $\begin{array}{c}95.51 \\
(-)\end{array}$ \\
\hline $\begin{array}{c}\text { Air mass, } \\
\text { PW, } \\
\text { AOD }_{500}\end{array}$ & $\begin{array}{c}238.97 \\
(+0.6 \%)\end{array}$ & $\begin{array}{l}206.09 \\
(+2.4 \%)\end{array}$ & $\begin{array}{c}184.52 \\
\mathbf{( + 2 . 3 \% )}\end{array}$ & $\begin{array}{c}208.36 \\
(+2.7 \%)\end{array}$ & $\begin{array}{c}74.93 \\
(-27.5 \%)\end{array}$ \\
\hline $\begin{array}{c}\text { Air mass, } \\
\text { PW }\end{array}$ & $\begin{array}{l}236.08 \\
(-0.6 \%)\end{array}$ & $\begin{array}{c}235.12 \\
(+16.9 \%)\end{array}$ & $\begin{array}{c}217.71 \\
(+20.7 \%)\end{array}$ & $\begin{array}{c}252.97 \\
(+24.7 \%)\end{array}$ & $\begin{array}{c}130.04 \\
(+36.2 \%)\end{array}$ \\
\hline Air mass & $\begin{array}{l}235.38 \\
(-0.9 \%)\end{array}$ & $\begin{array}{c}234.00 \\
(+16.3 \%)\end{array}$ & $\begin{array}{c}217.15 \\
(+\mathbf{2 0 . 4 \% )}\end{array}$ & $\begin{array}{c}252.50 \\
(+24.4 \%)\end{array}$ & $\begin{array}{c}167.12 \\
(+\mathbf{7 5 . 0 \%})\end{array}$ \\
\hline
\end{tabular}

Table 4 - Simulated energy yields for a single module at five locations, with various levels of atmospheric data knowledge. Percentage deviation from the best effort yield in each location is shown in bracketed bold text. In the basic case, only air mass is known. In the most detailed simulations, air mass, precipitable water, $\mathrm{AOD}_{500}$, Angström Exponent and are all used. 


\begin{tabular}{|l|l|}
\hline Parameter & Value \\
\hline Installed Cost $(\$ / \mathrm{W})$ & 2.5 \\
\hline Size of Plant & $500 \mathrm{MW}$ \\
\hline Operation and maintenance (\$/W per year) & 0.01 \\
\hline Project lifetime (years) & 30 \\
\hline Discount rate $(\%)$ & 5 \\
\hline Energy yield degradation rate $\%$ per year) & 0.5 \\
\hline Total capital cost (\$USD) & $3 \times 10^{9}$ \\
\hline Percentage of capital cost paid up front $(\%)$ & 100 \\
\hline Annual insurance cost $(\$ \cup S D)$ & $15 \times 10^{6}$ \\
\hline
\end{tabular}

Table 5 - List of values used in the LCOE calculations, the basis for these assumptions can be found in $[42,44,45]$

\begin{tabular}{|c|c|c|c|}
\hline \multirow{2}{*}{ Detail Level } & \multicolumn{3}{|c|}{ LCOE (\$USD/kWh) } \\
\cline { 2 - 4 } & Rogers Dry Lake & Tamanrasset & Jaipur \\
\hline $\begin{array}{c}\text { Air mass, PW, } \\
\text { AOD }_{500}, \text { Angström } \\
\text { Exponent }\end{array}$ & 0.076 & 0.090 & 0.190 \\
\hline $\begin{array}{c}\text { Air mass, PW, } \\
\text { AOD }_{500}\end{array}$ & 0.076 & 0.088 & 0.243 \\
\hline Air mass, PW & 0.077 & 0.077 & 0.140 \\
\hline Air mass & 0.077 & 0.078 & 0.109 \\
\hline$\Delta L C O E(\%)$ & $-1.3 \%$ & $+15.4 \%$ & $+74.3 \%$ \\
\hline
\end{tabular}

Table 6 - Estimated Levelized Cost of Energy (LCOE) for CPV systems sited at Rogers Dry Lake, Tamanrasset and Jaipur. All costings are in $\$$ USD/kWh. 


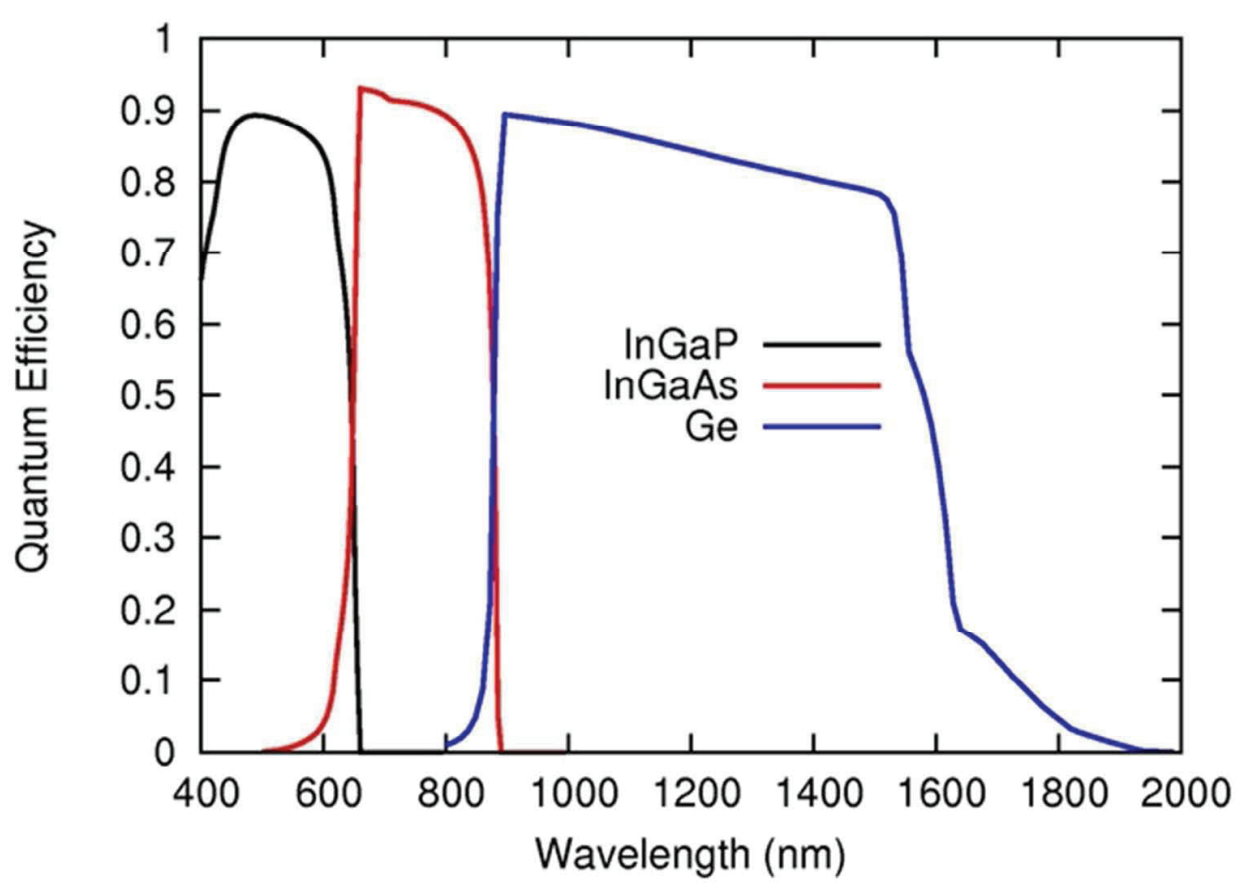

External Quantum Efficiencies for the triple-junction InGaP/InGaAs/Ge solar cell investigated in this publication. Further details can be found in [9]. $53 \times 37 \mathrm{~mm}(300 \times 300 \mathrm{DPI})$ 


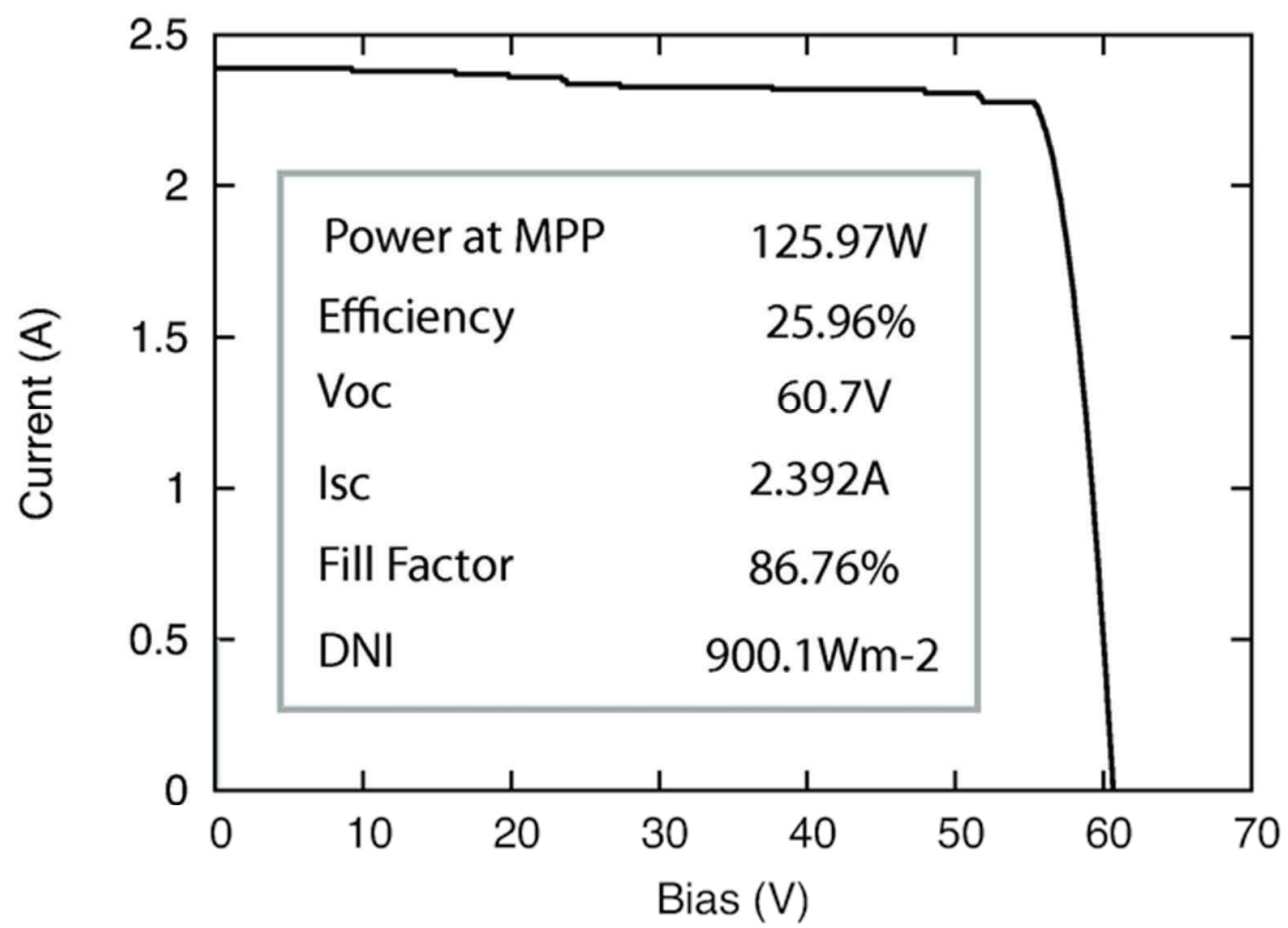

Simulated current-voltage characteristics at AM1.5D reference spectral conditions, $T=298 \mathrm{~K}$ $52 \times 38 \mathrm{~mm}(300 \times 300 \mathrm{DPI})$ 


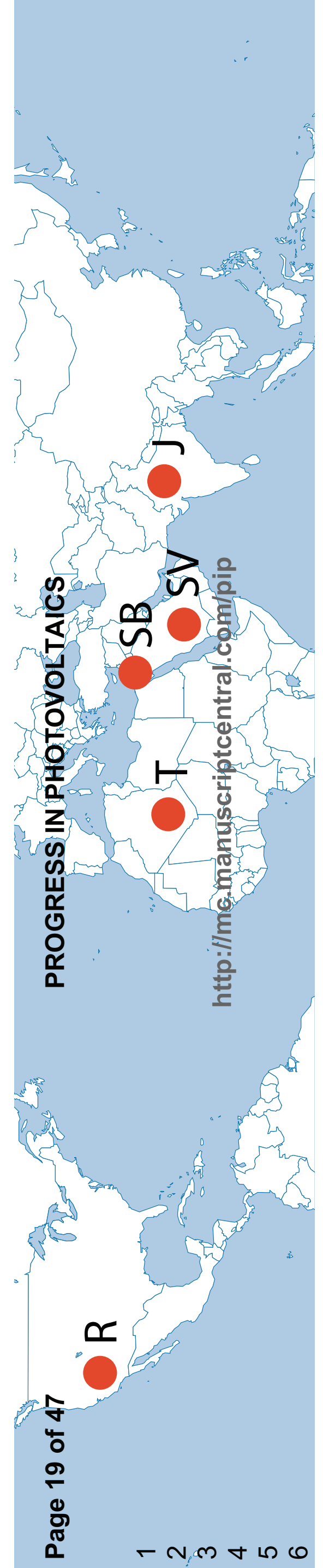




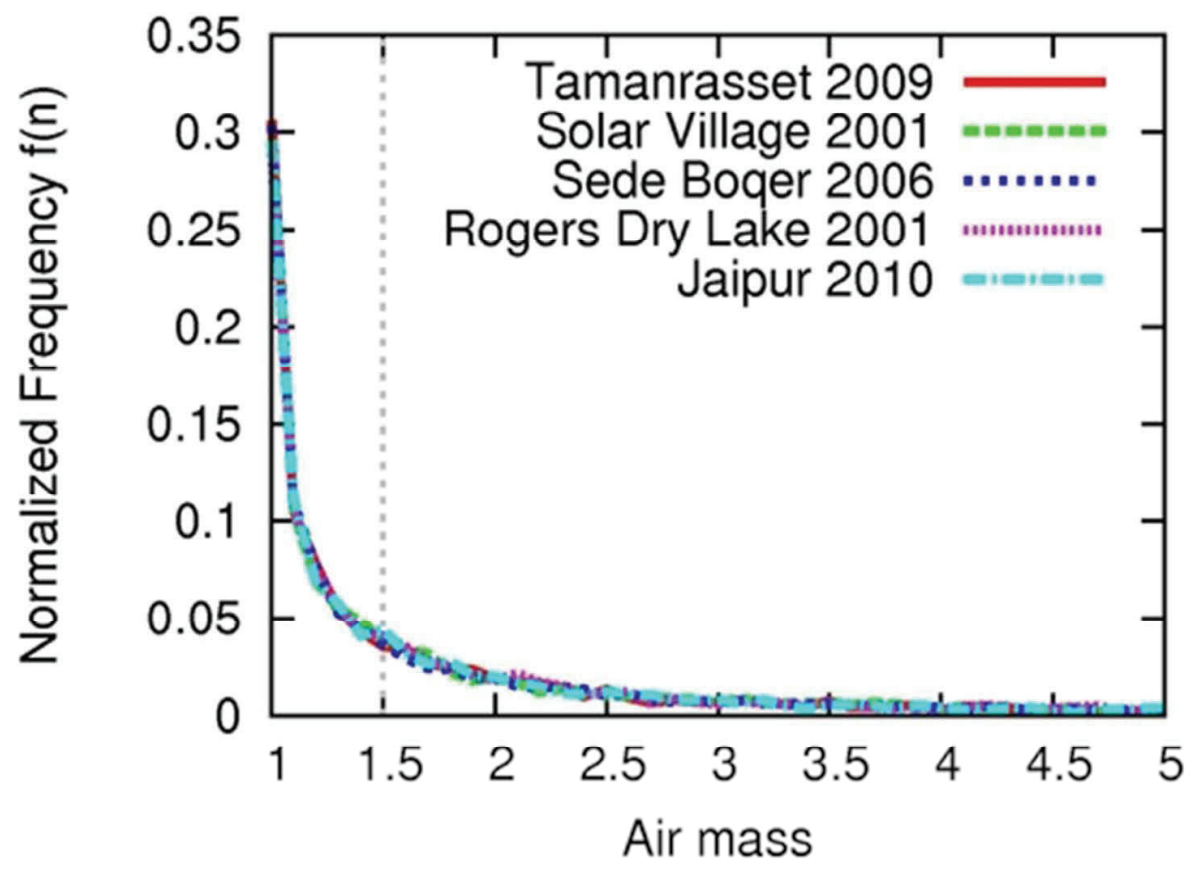

Normalized frequency distribution of air mass $44 \times 31 \mathrm{~mm}(300 \times 300 \mathrm{DPI})$ 


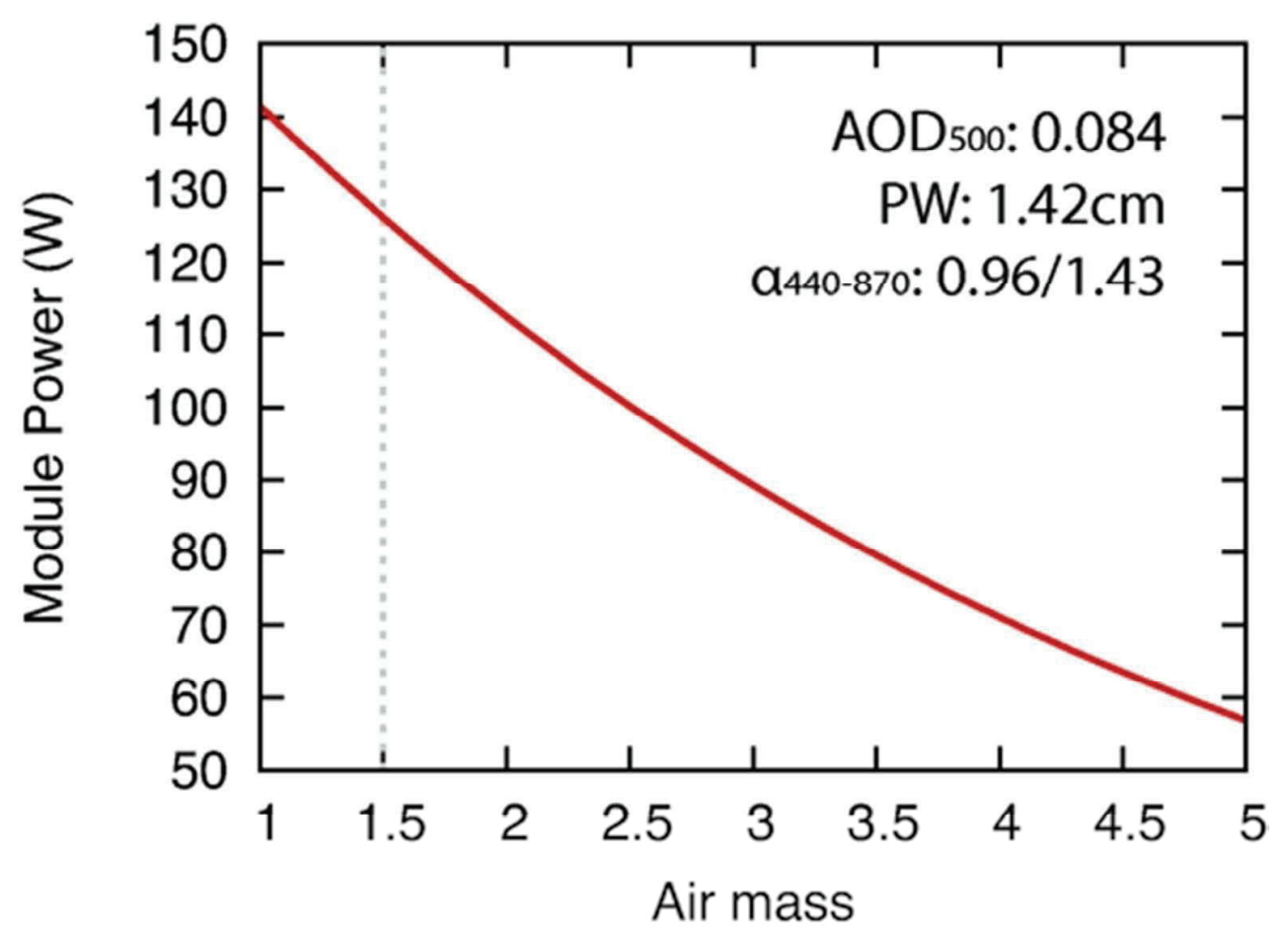

Power response of CPV module to changing air mass. For this particular system, power output generally decreases with greater air mass. All other conditions are maintained at reference values described in Table 1. Grey dotted line indicates the value (1.5) used to generate the AM1.5D reference spectrum. $43 \times 32 \mathrm{~mm}(300 \times 300$ DPI $)$ 


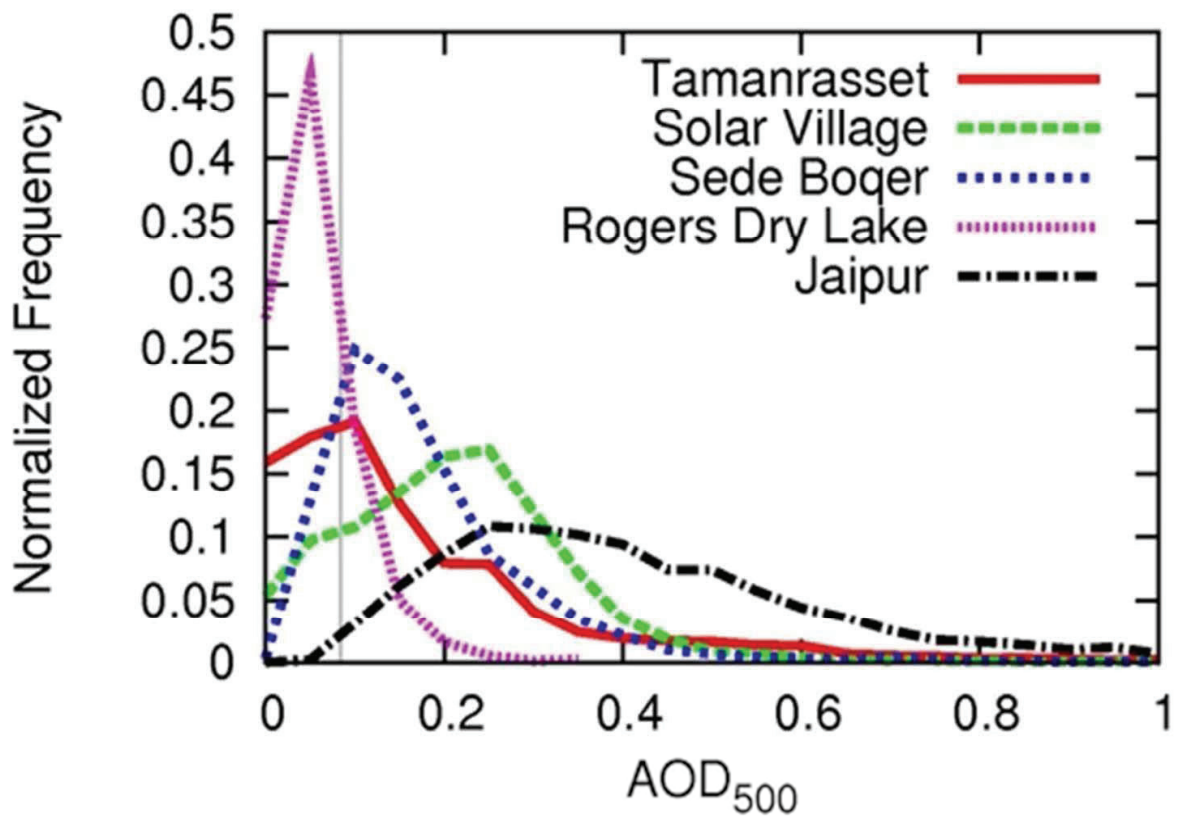

Normalized frequency distribution for Aerosol Optical Depth at 500nm (AOD500) for various locations, extracted from AERONET database. Grey vertical line indicates the value $(0.084)$ used to generate the AM1.5D reference spectrum.

$44 \times 31 \mathrm{~mm}$ (300 x 300 DPI) 


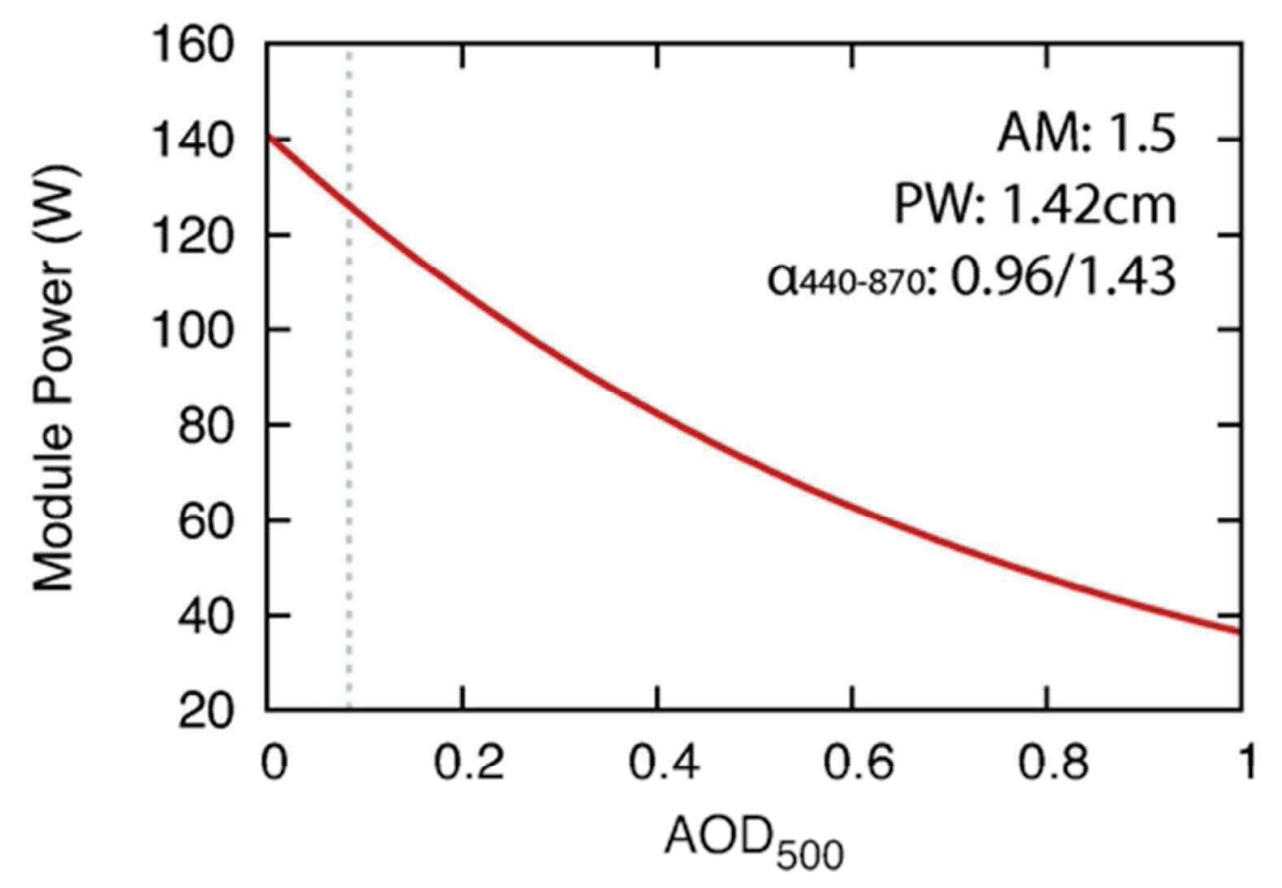

Power response of CPV module to varying AOD500. Decreasing power is seen as with AOD500 increases. All other conditions are maintained at reference values described in Table 1. $41 \times 29 \mathrm{~mm}(300 \times 300 \mathrm{DPI})$ 


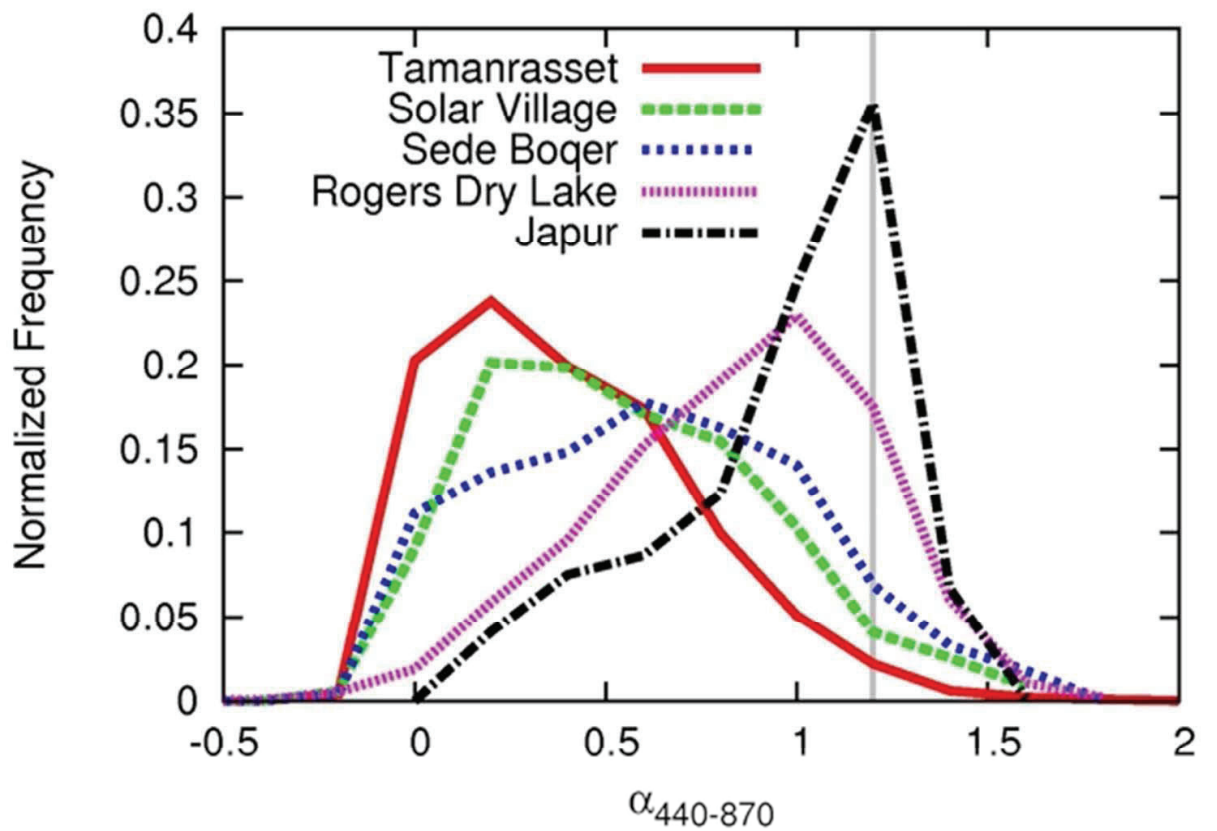

Normalized frequency distribution for Angström Exponent, evaluated between 440 and 870nm (a440-870), for various locations and extracted from AERONET database. Grey vertical line indicates the mean value (1.2) used to generate the $A M 1.5 \mathrm{D}$ reference spectrum.aad $53 \times 37 \mathrm{~mm}(300 \times 300 \mathrm{DPI})$ 


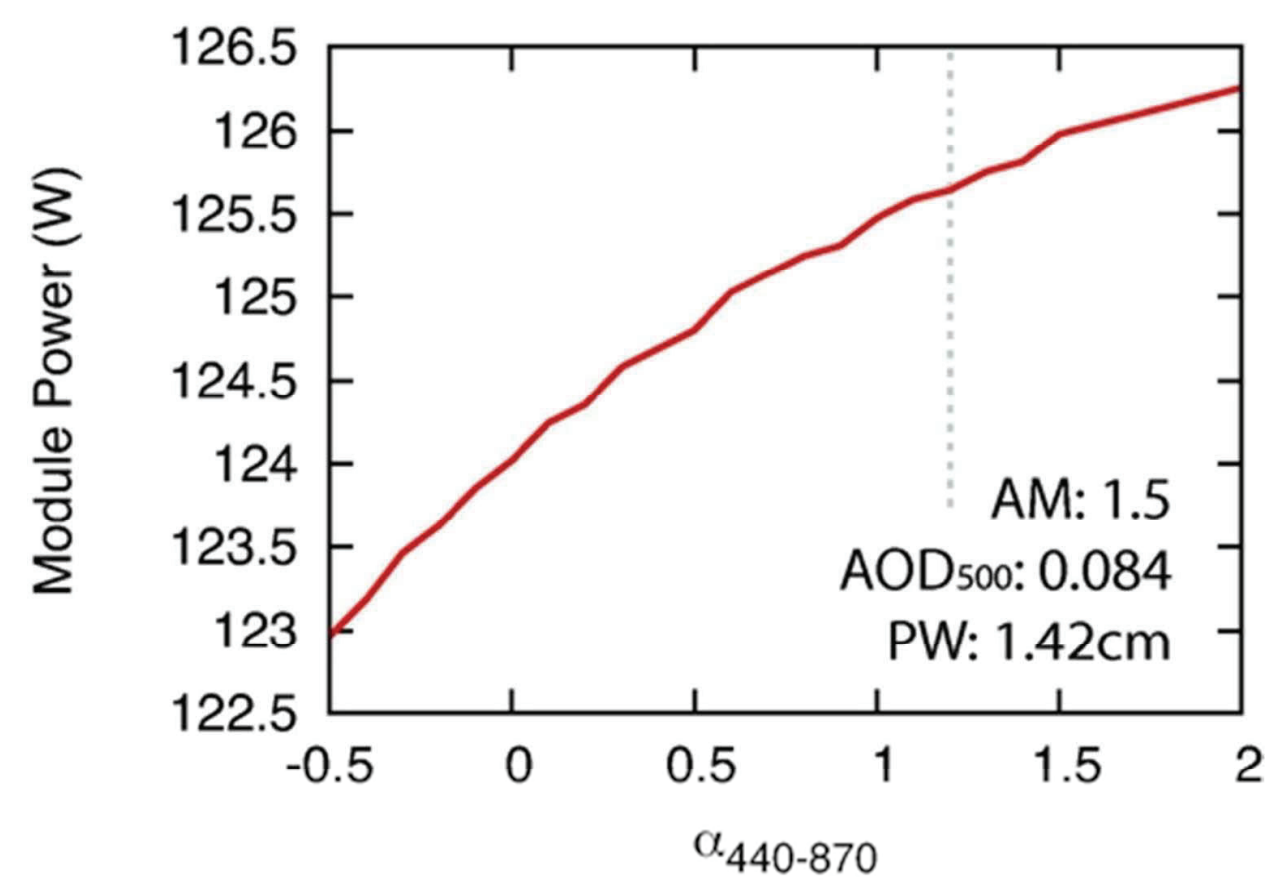

Power response of CPV module to changing Angström Exponent. All other conditions are maintained at reference values described in Table 1. $41 \times 29 \mathrm{~mm}(300 \times 300 \mathrm{DPI})$ 


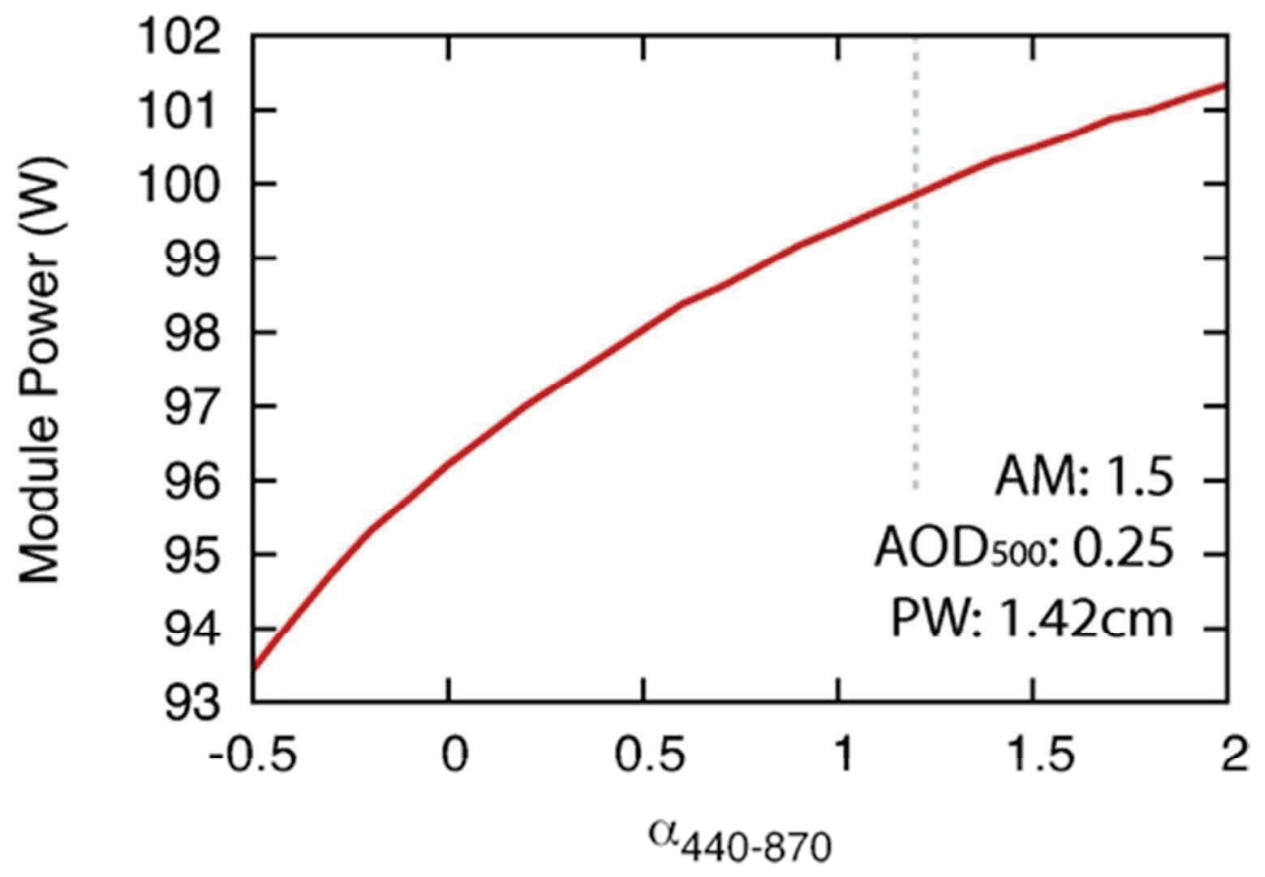

Power response of CPV module to changing Angström Exponent at high AOD values. $41 \times 29 \mathrm{~mm}(300 \times 300$ DPI $)$ 
a.

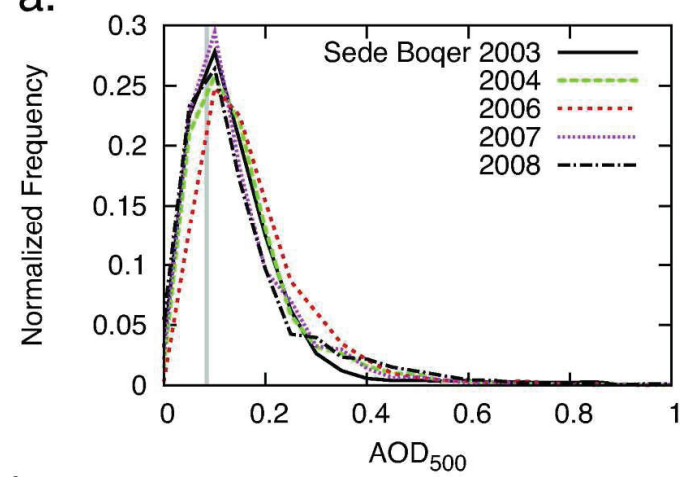

b.

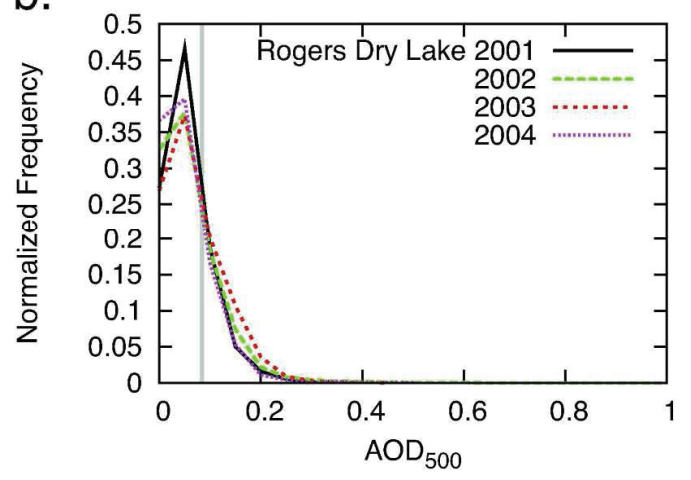

C.

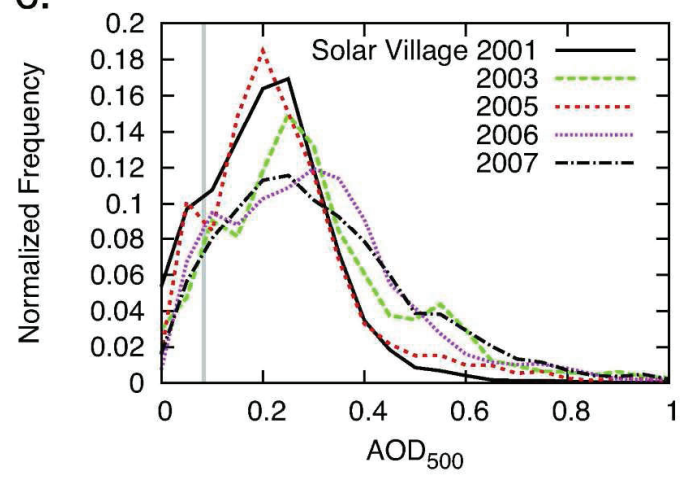

Normalized frequency distributions for Aerosol Optical Depth at 500nm (AOD500) at Sede Boqer (top), Rogers Dry Lake (middle) and Solar Village (bottom) during the years indicated. Grey vertical line indicates the value $(0.084)$ used to generate the AM1.5D reference spectrum. $133 \times 302 \mathrm{~mm}(300 \times 300$ DPI $)$ 


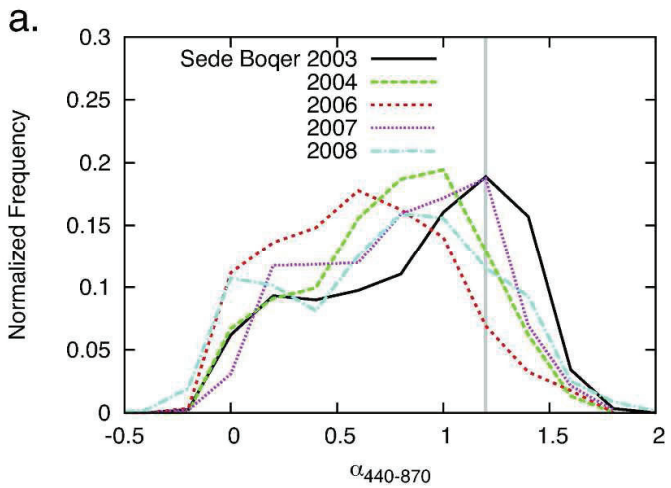

b.

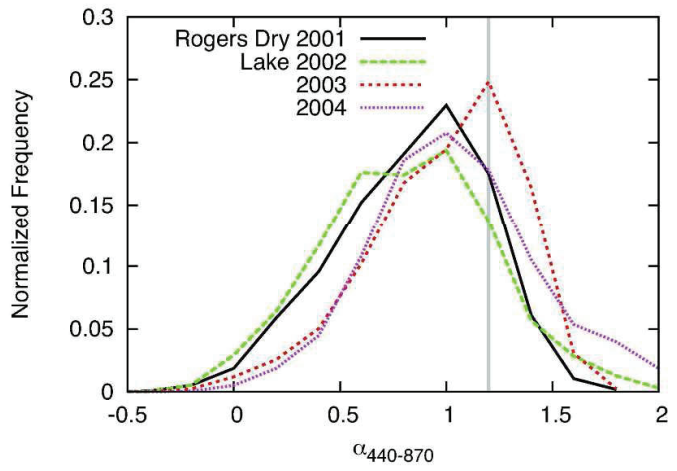

C.

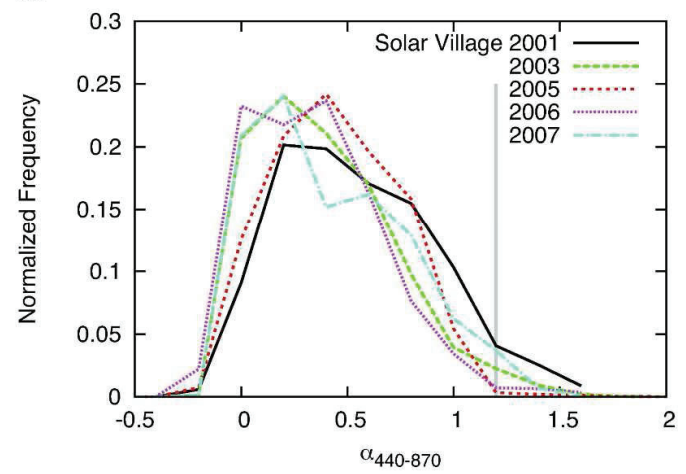

Normalized frequency distribution for Angstrom Exponent (a440-870) at Sede Boqer (top), Rogers Dry Lake (middle) and Solar Village (bottom) over multiple years. Grey vertical line indicates the mean value (1.2) used to generate the AM1.5D reference spectrum. The sites were selected for comparison due to availability of long-term data. $164 \times 375 \mathrm{~mm}$ (300 x 300 DPI) 


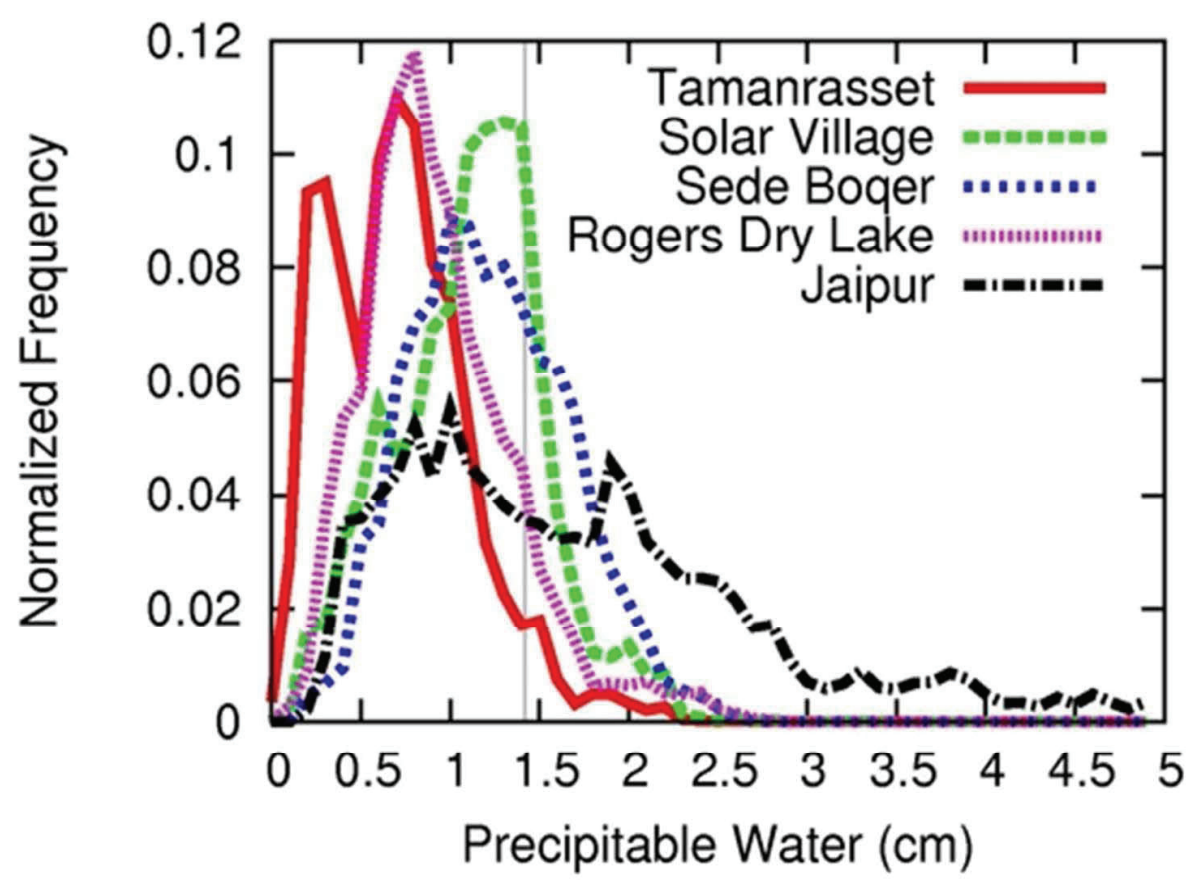

Normalized frequency distribution of precipitable water for various locations, extracted from AERONET database. Grey line indicates the value $(1.42 \mathrm{~cm})$ used to generate the AM1.5D reference spectrum. $44 \times 31 \mathrm{~mm}(300 \times 300 \mathrm{DPI})$ 


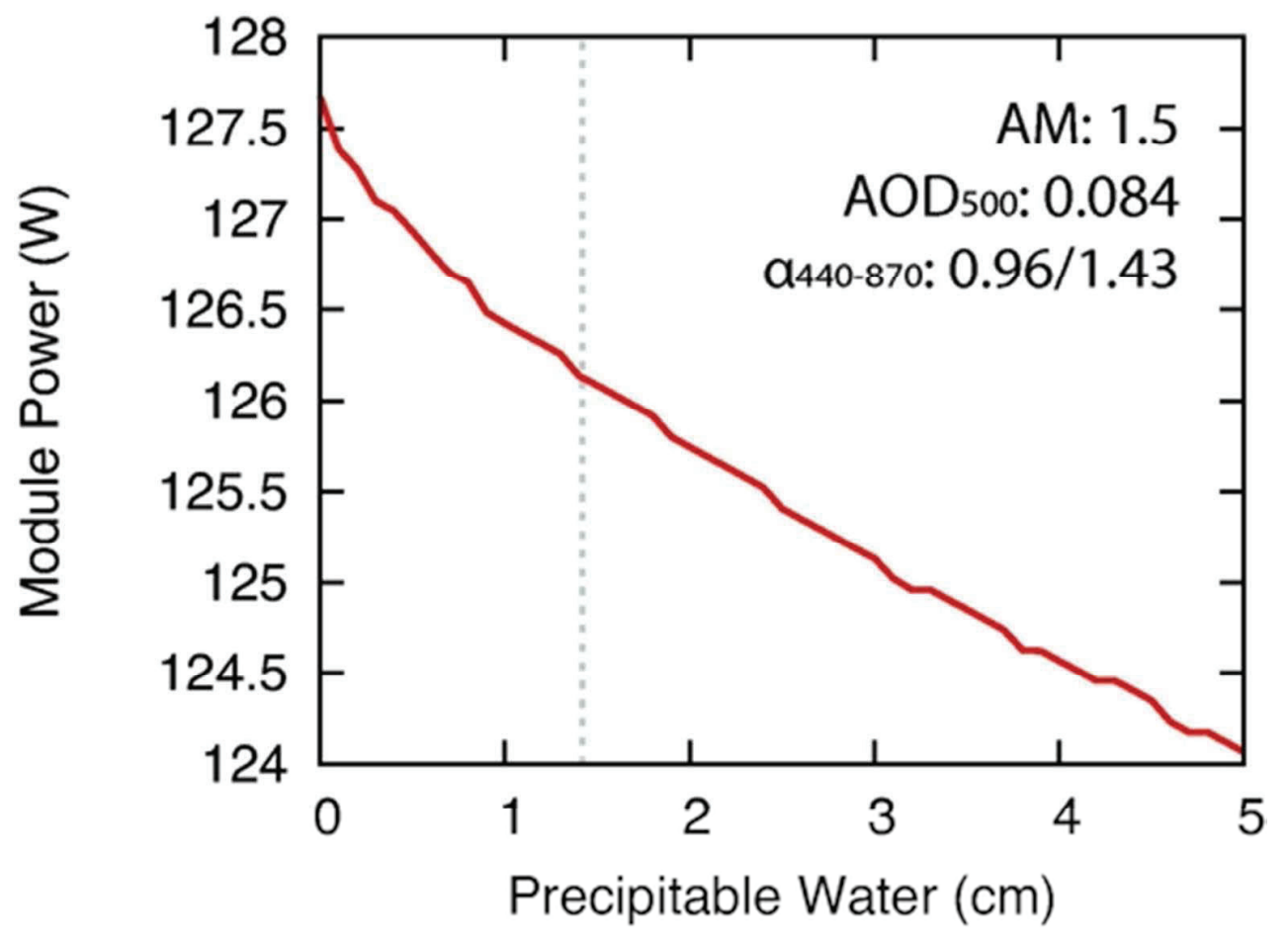

Power response of CPV module to varying precipitable water. All other conditions are maintained at reference values described in Table 1. $43 \times 32 \mathrm{~mm}(300 \times 300$ DPI $)$ 


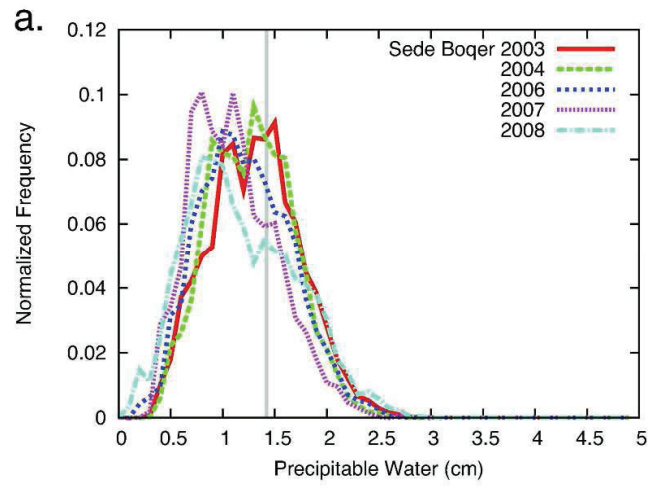

b.

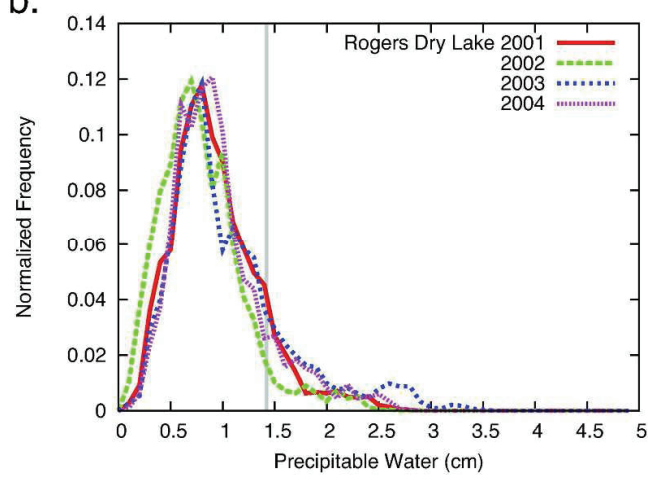

C.

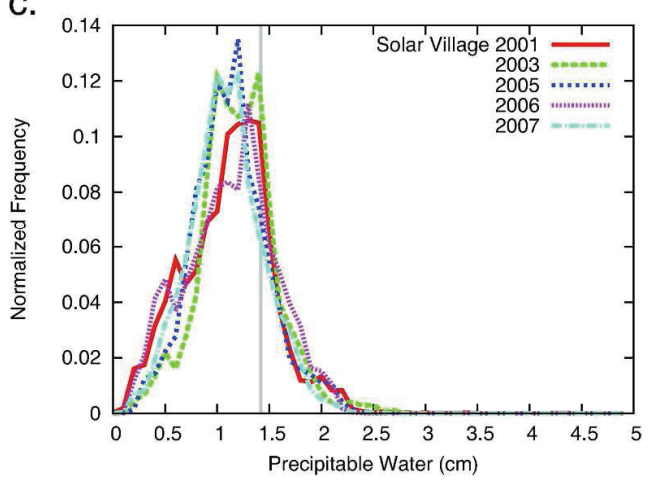

Normalized frequency distribution of precipitable water for multiple years at Sede Boqer (top), Rogers Dry Lake (middle) and Solar Village (bottom), data extracted from AERONET database. Grey vertical line indicates the value $(1.42 \mathrm{~cm})$ used to generate the AM1.5D reference spectrum. $167 \times 397 \mathrm{~mm}(300 \times 300 \mathrm{DPI})$ 


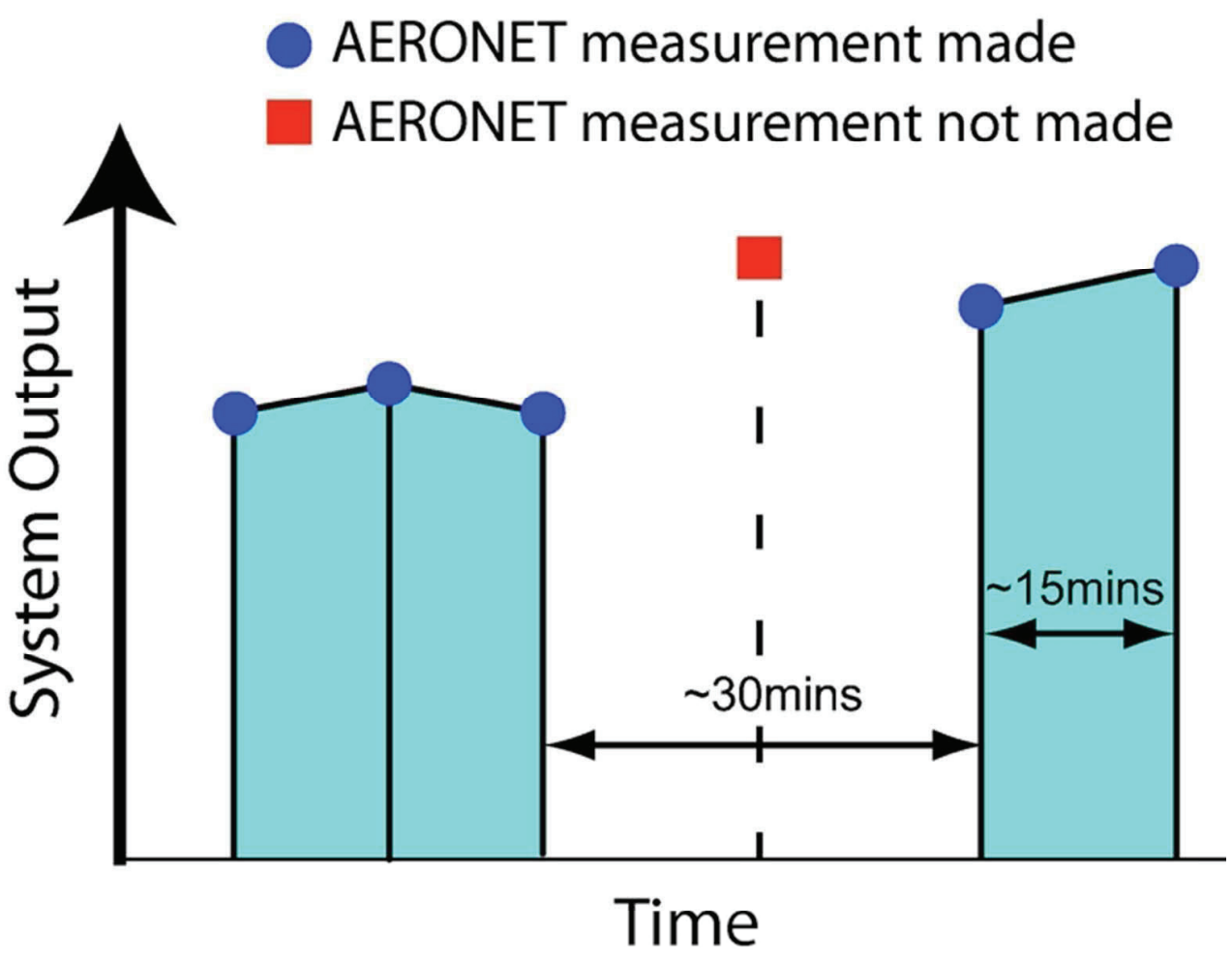

Schematic of integration approach - given an air mass of lower than 7, AERONET measurements are made approximately every 15 minutes. We assume data gaps of 30 minutes or greater are due to cloudy conditions, and do not include them in our calculation of energy yield. $61 \times 51 \mathrm{~mm}(300 \times 300 \mathrm{DPI})$ 


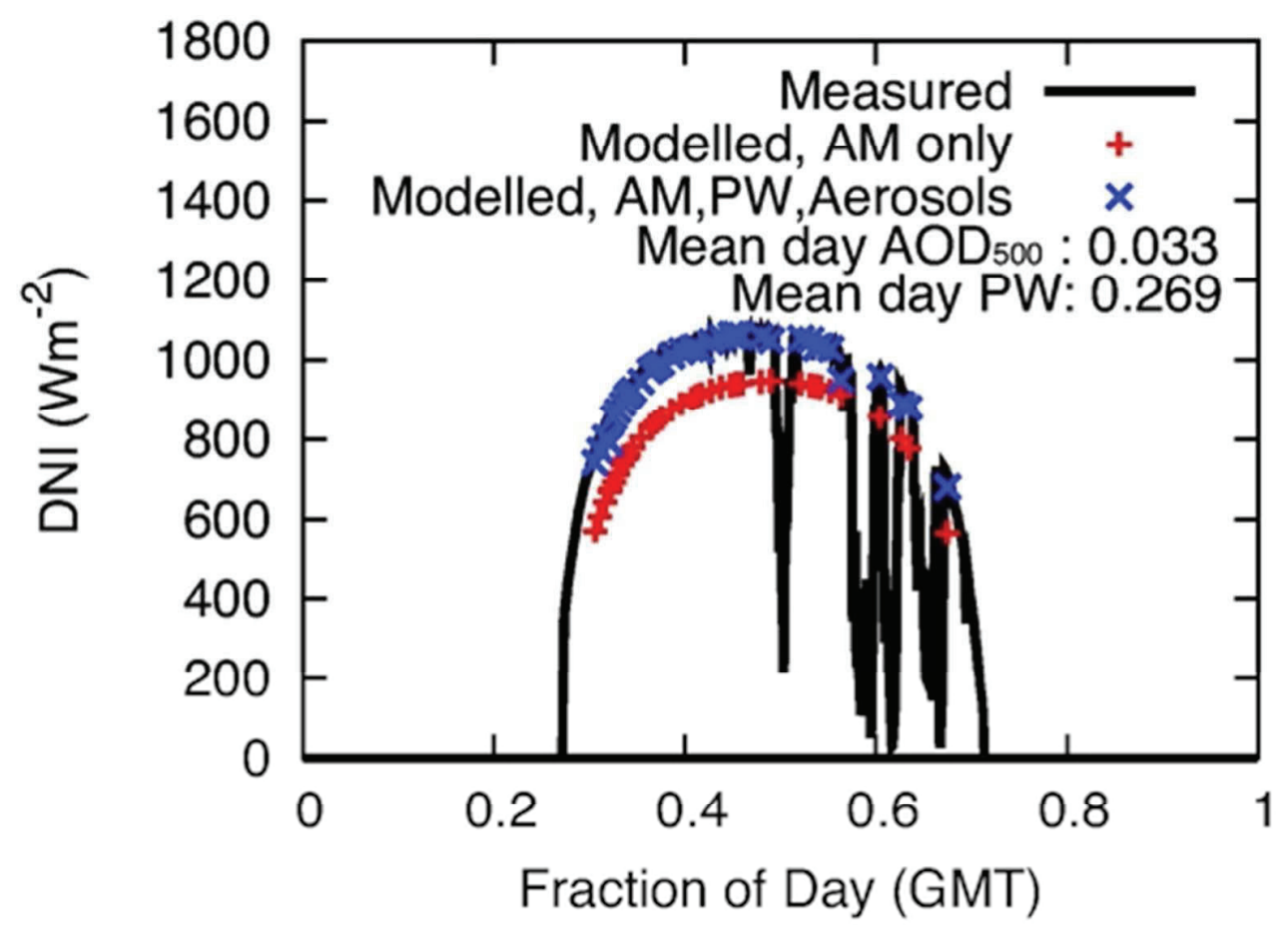

Measured DNI and modelled cloudless DNI on 2007-01-12 at Tamanrasset. $43 \times 31 \mathrm{~mm}(300 \times 300$ DPI $)$ 


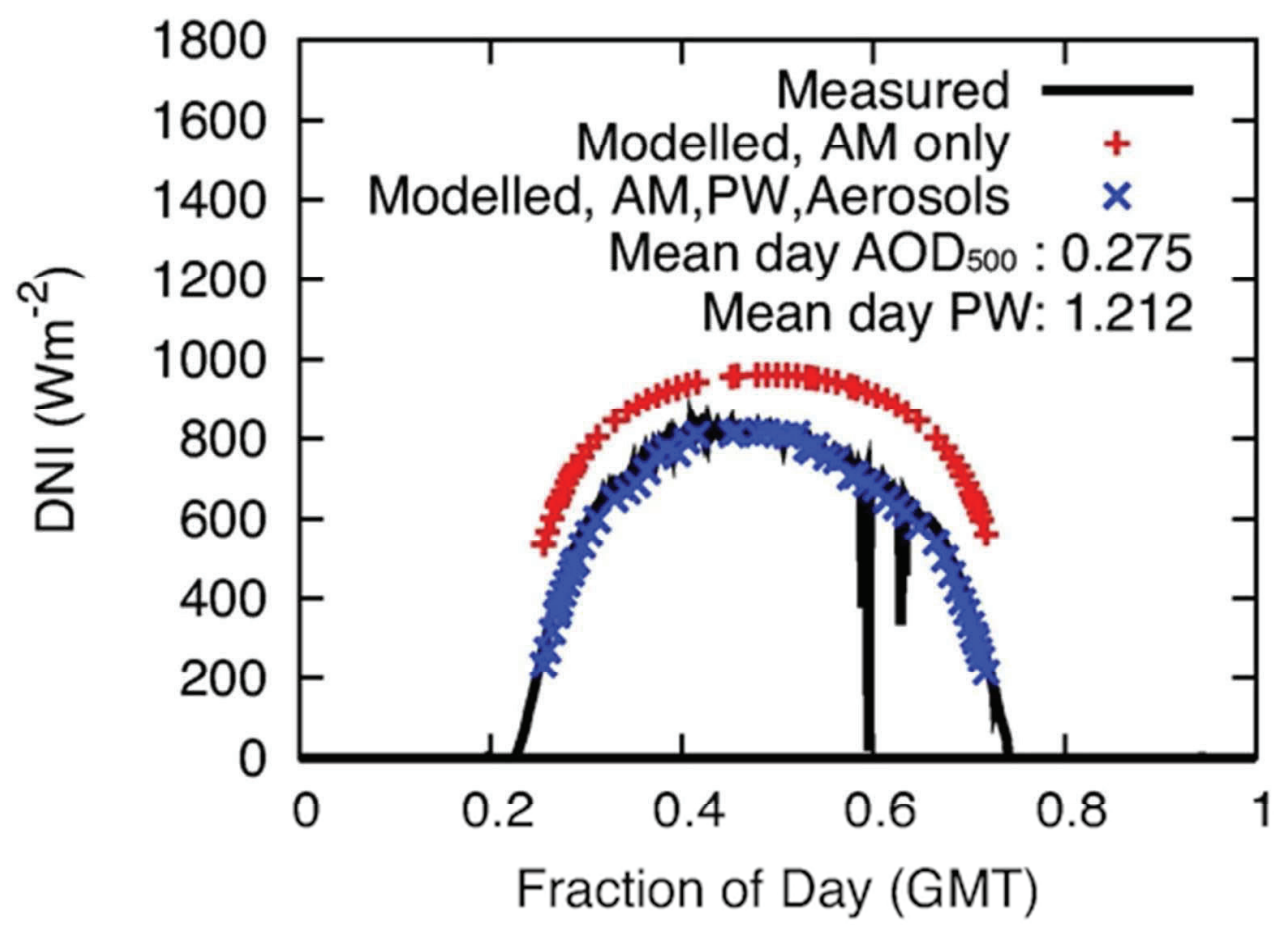

Measured DNI and modelled cloudless DNI on 2007-08-09 at Tamanrasset. $43 \times 31 \mathrm{~mm}(300 \times 300$ DPI $)$ 


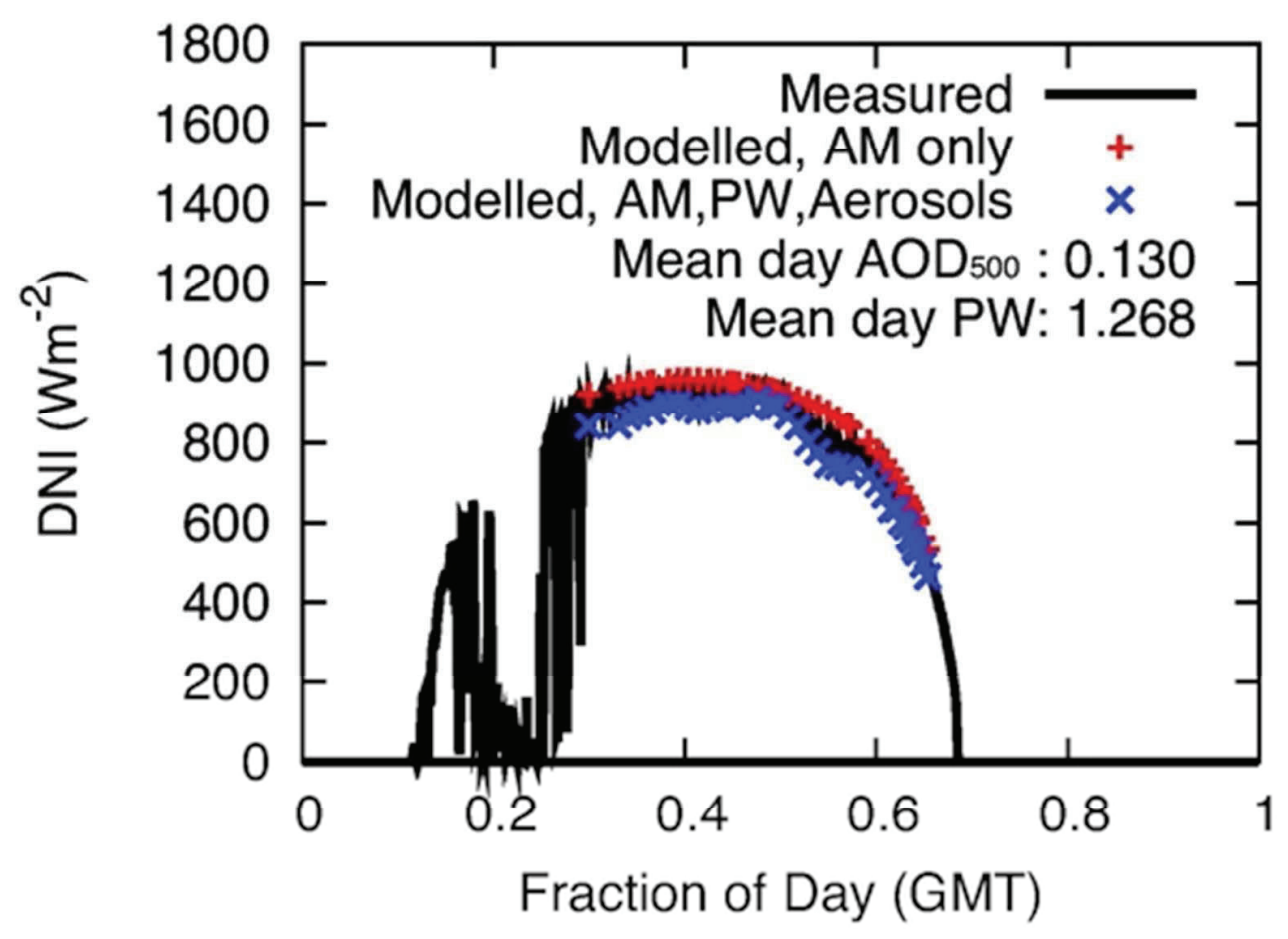

Measured DNI and modelled cloudless DNI on 2006-06-11 at Sede Boqer. $43 \times 31 \mathrm{~mm}(300 \times 300 \mathrm{DPI})$ 


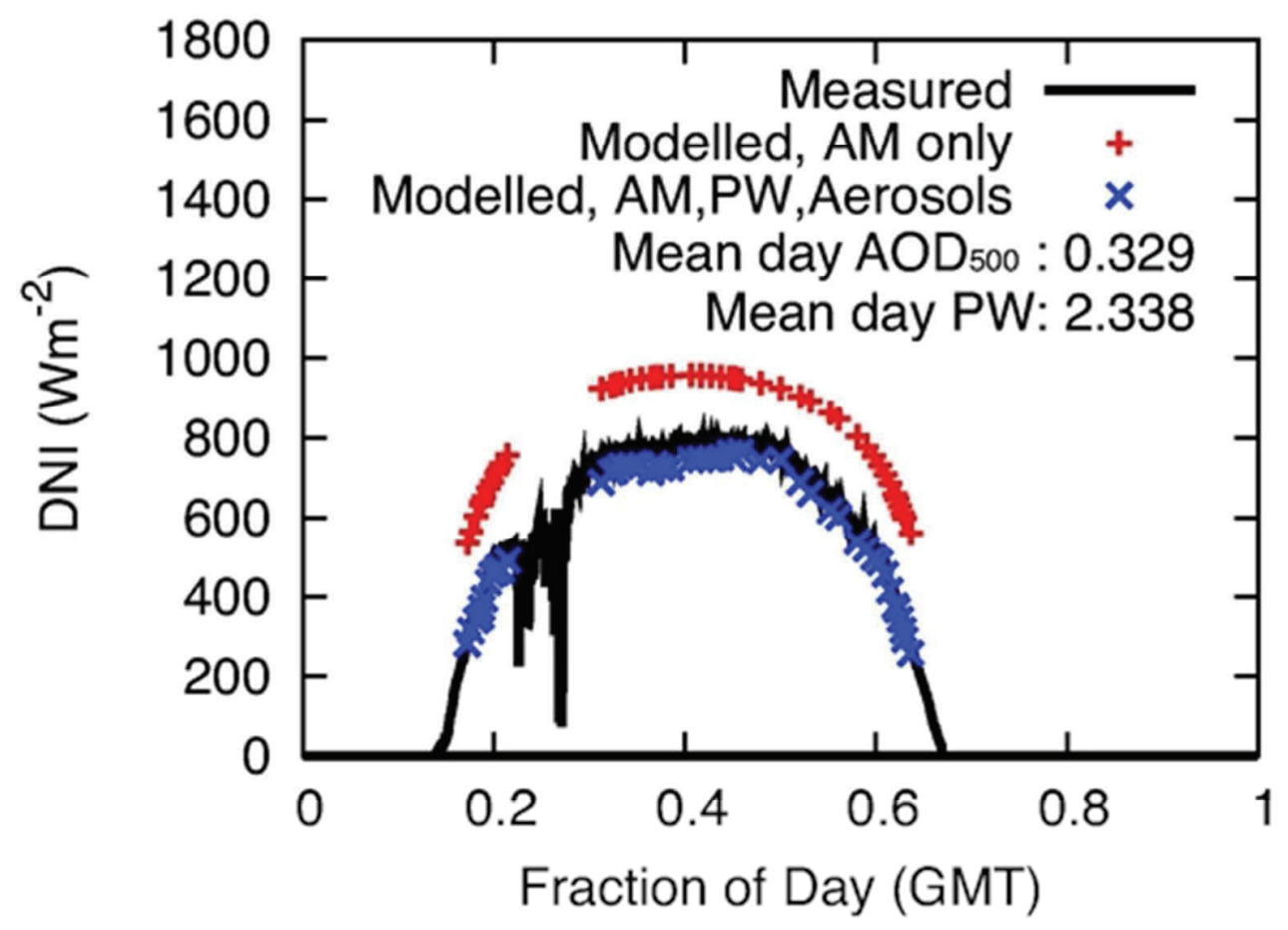

Measured DNI and modelled cloudless DNI on 2006-08-19 at Sede Boqer. $43 \times 31 \mathrm{~mm}(300 \times 300 \mathrm{DPI})$ 


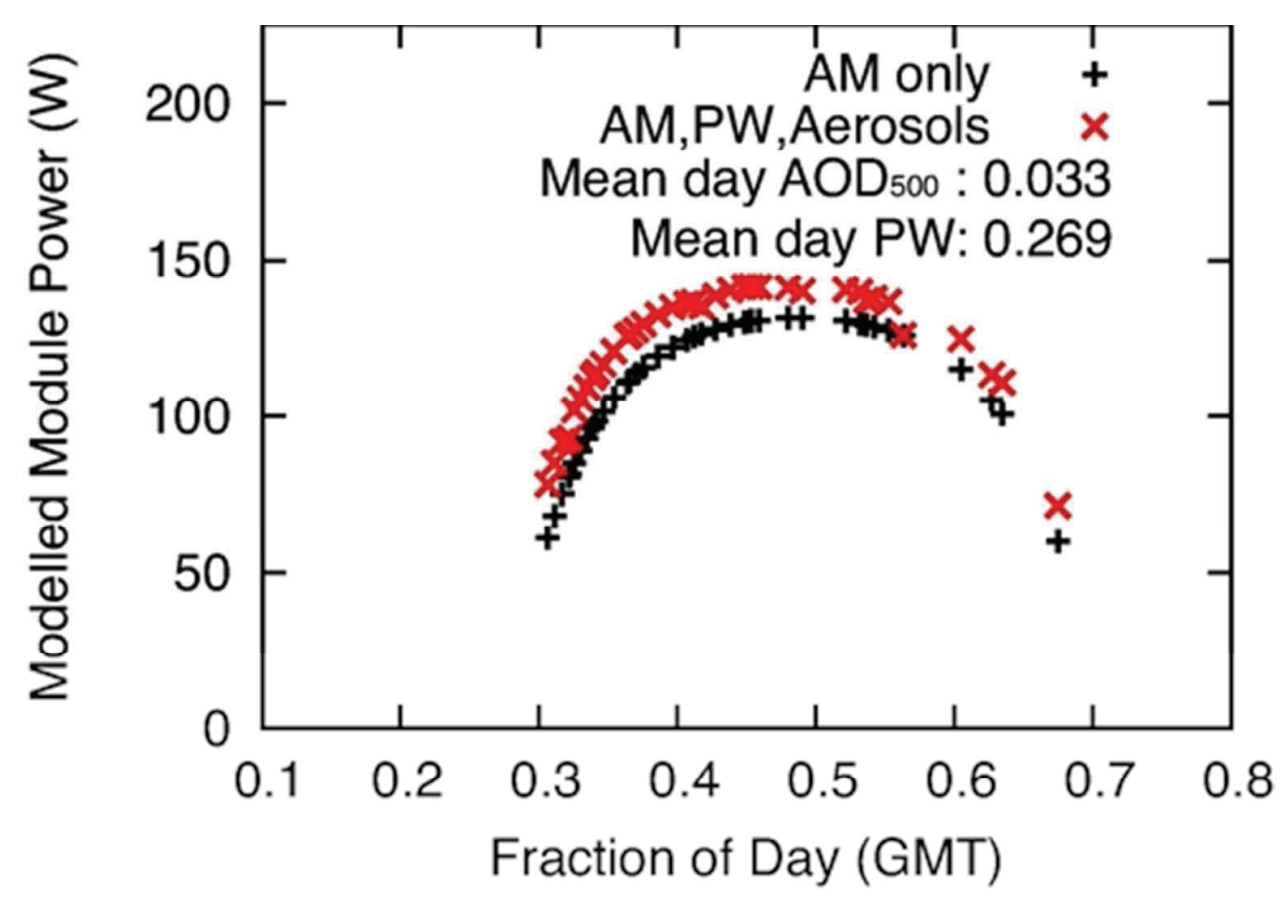

Modelled module power output on 2007-01-12 at Tamanrasset. $41 \times 29 \mathrm{~mm}(300 \times 300$ DPI $)$ 


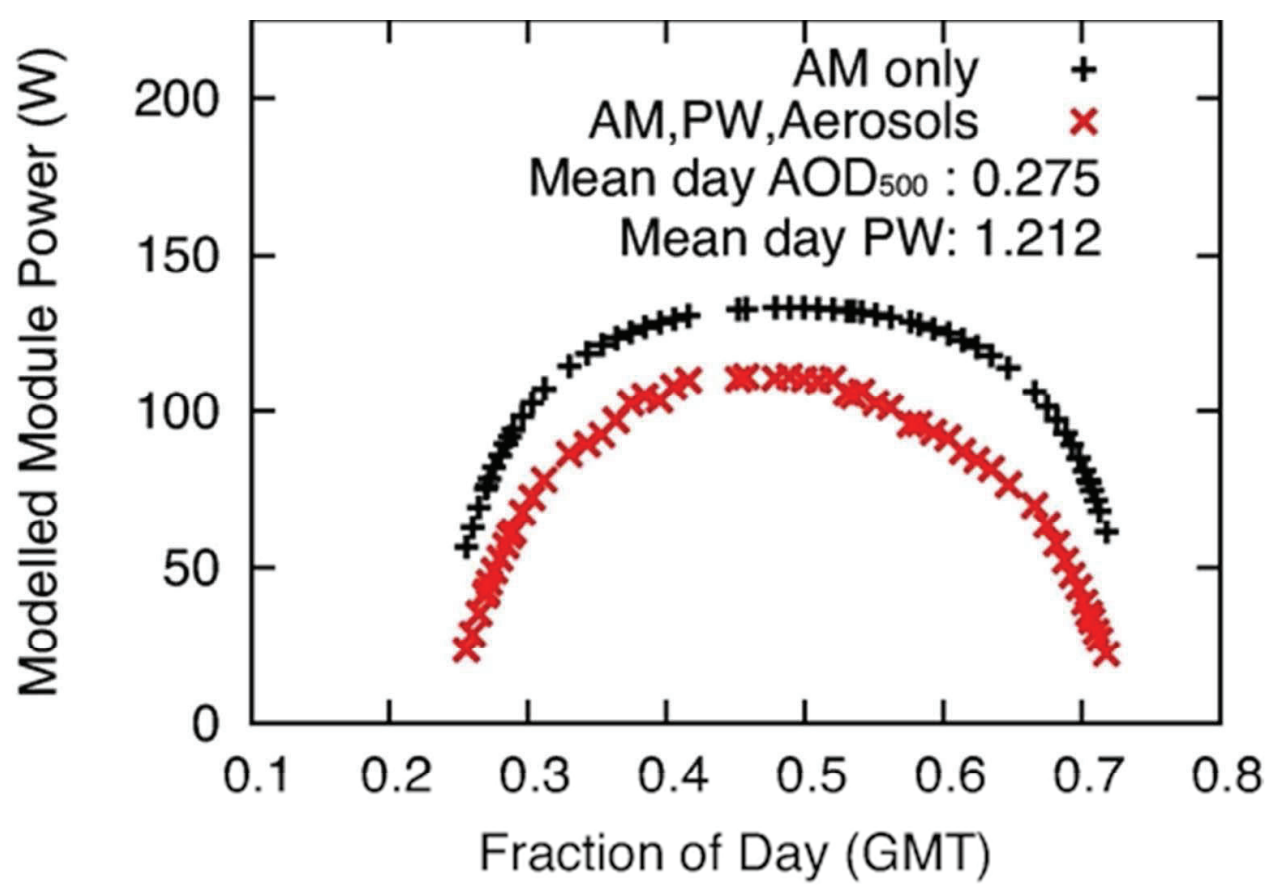

Modelled module power output on 2007-08-09 at Tamanrasset. $41 \times 29 \mathrm{~mm}(300 \times 300 \mathrm{DPI})$ 


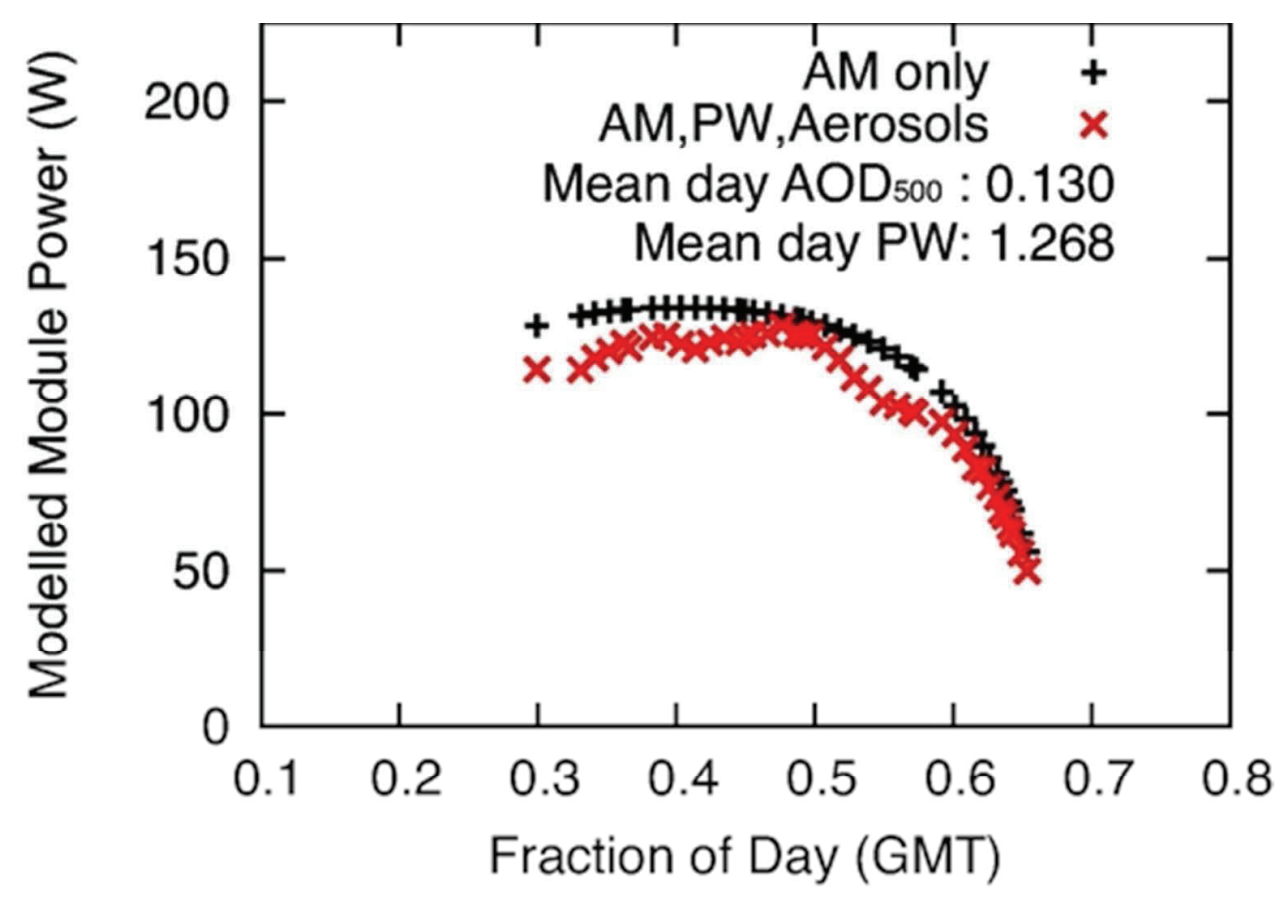

Modelled module power output on 2006-06-11 at Sede Boqer. $41 \times 29 \mathrm{~mm}(300 \times 300 \mathrm{DPI})$ 


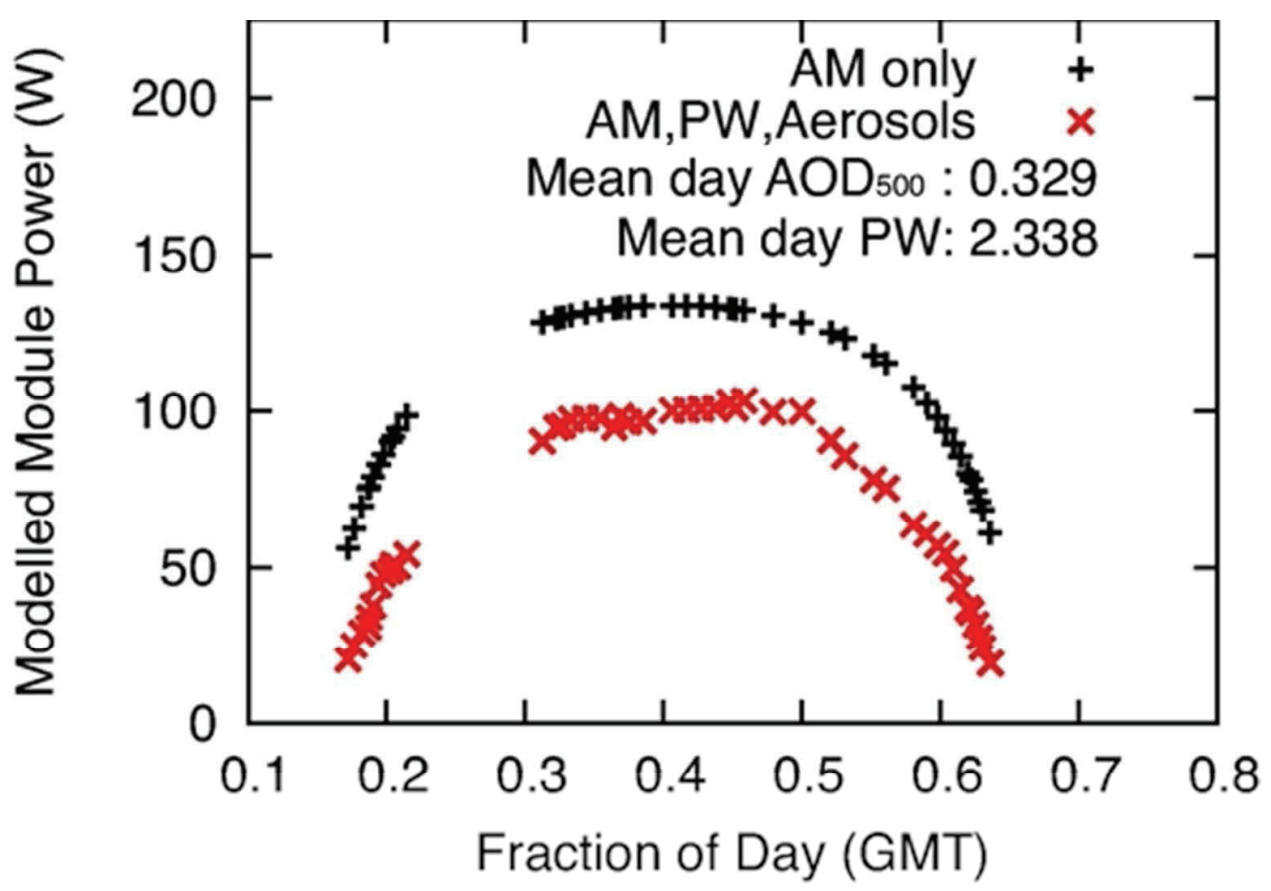

Modelled module power output on 2006-08-19 at Sede Boqer. $41 \times 29 \mathrm{~mm}(300 \times 300 \mathrm{DPI})$ 


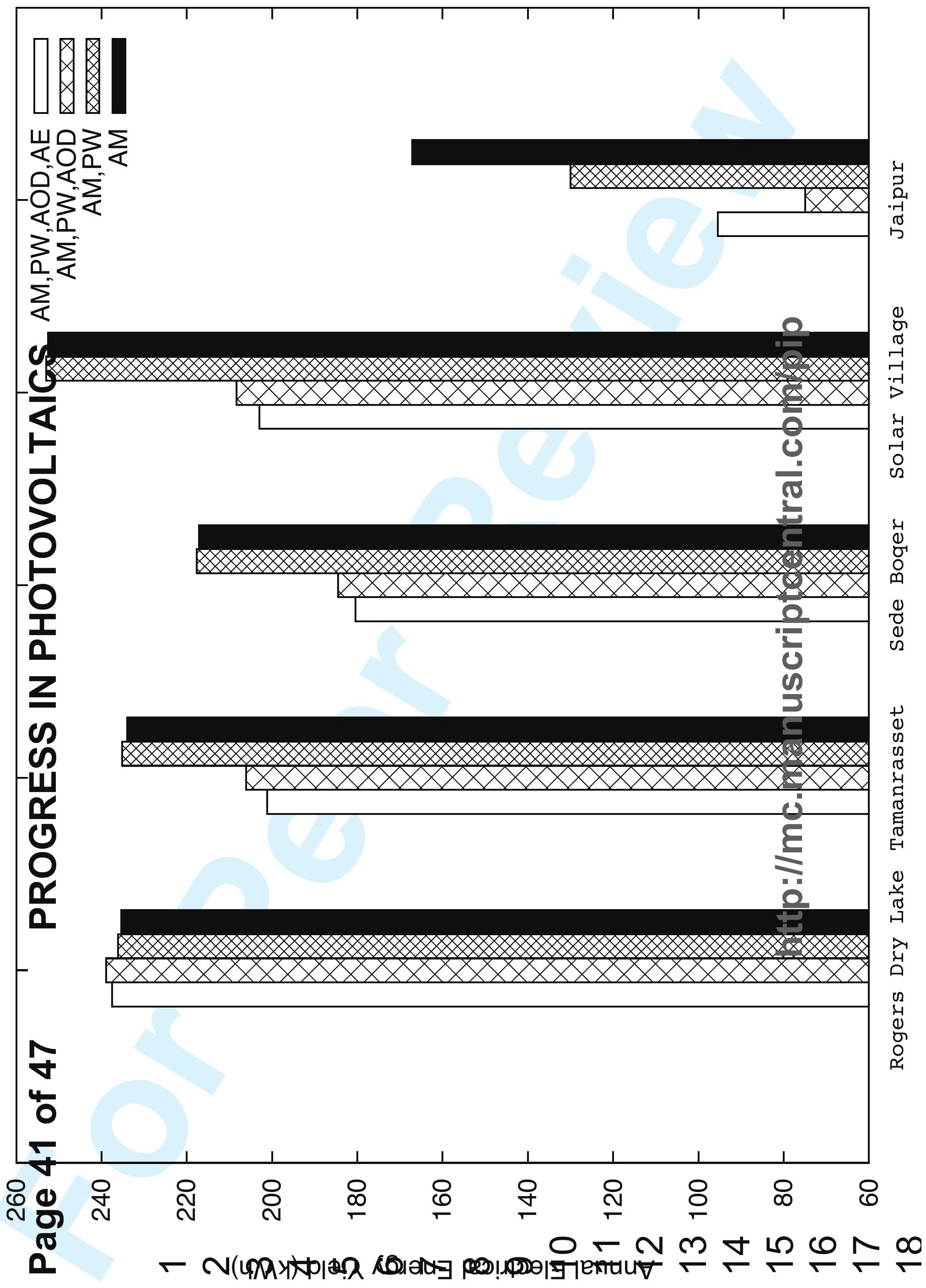




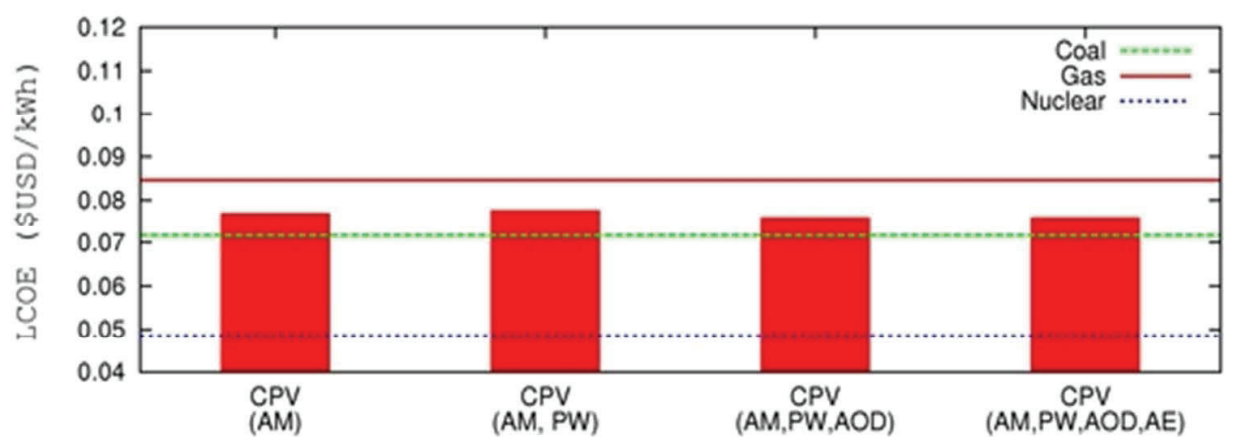

Levelized Cost of Energy from a hypothetical 500MW CPV power plant for USA. Energy yields from Rogers Dry Lake used. $44 \times 15 \mathrm{~mm}(300 \times 300 \mathrm{DPI})$ 


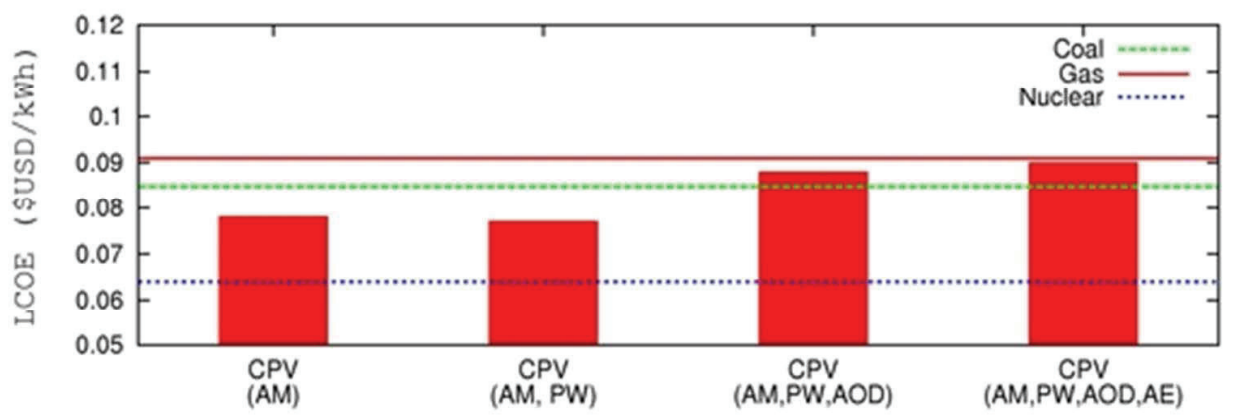

Levelized cost of energy from a hypothetical 500MW CPV power plant sited in North Africa, exporting energy to Europe. Energy yields from Tamanrasset used.

$44 \times 15 \mathrm{~mm}(300 \times 300$ DPI $)$ 


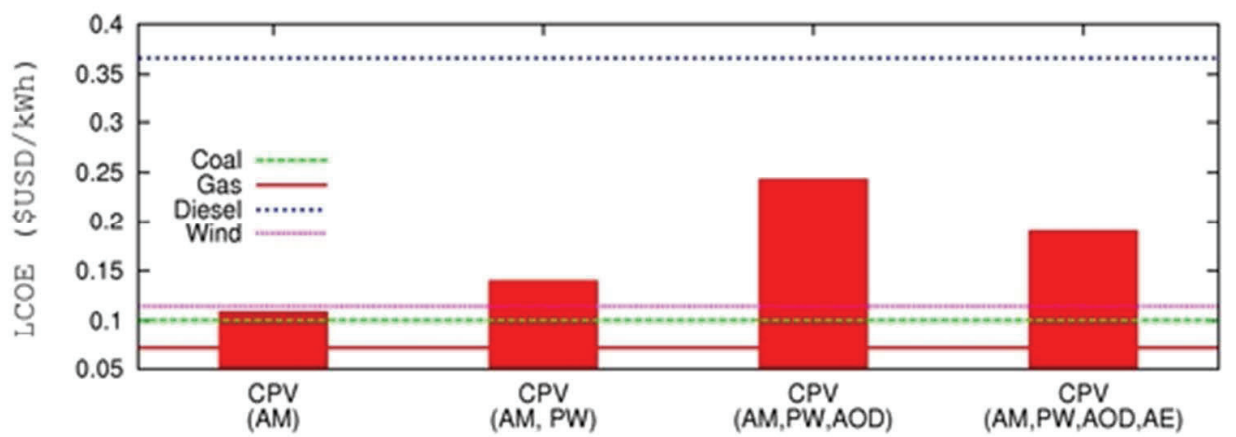

Levelized cost of energy from a hypothetical 500MW CPV power plant for India. Energy yields from Jaipur used. "Diesel" represents off-grid diesel generators. $44 \times 15 \mathrm{~mm}(300 \times 300$ DPI $)$ 


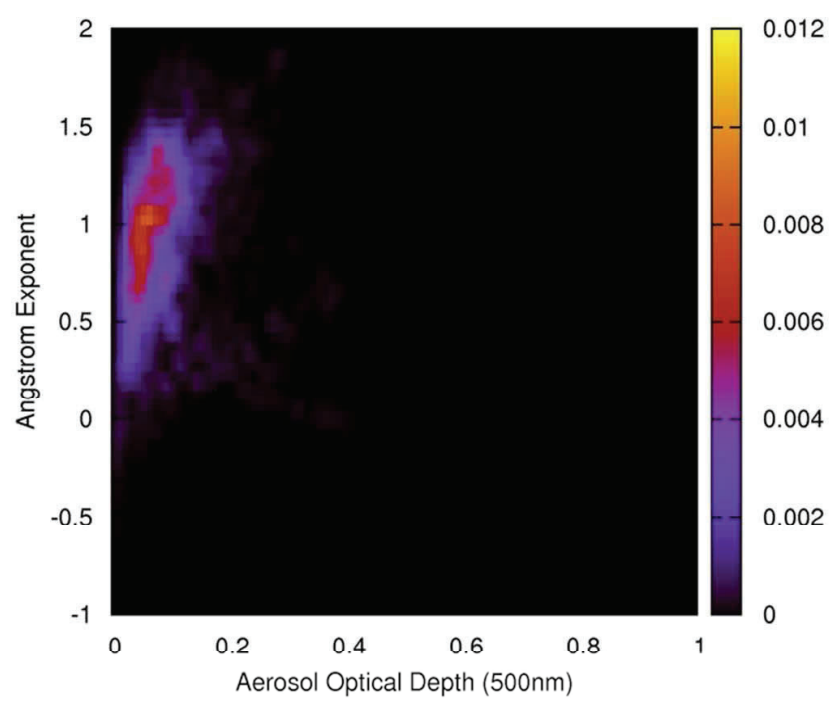

Normalised frequency contour map for aerosol optical depth and Angström Exponent, for Rogers Dry Lake during the period defined in Table 2 .

$88 \times 62 \mathrm{~mm}(300 \times 300 \mathrm{DPI})$ 


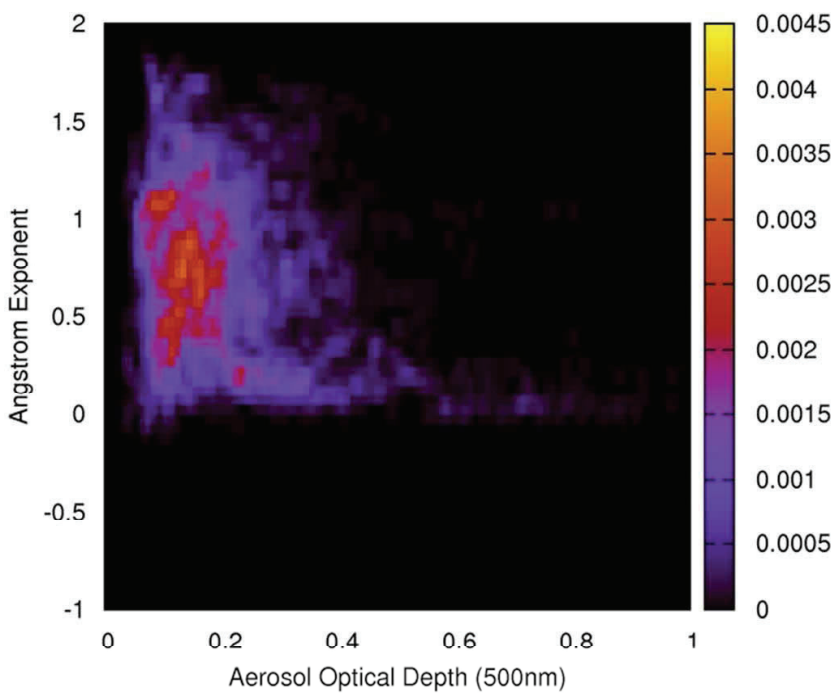

Normalised frequency contour map for aerosol optical depth and Angström Exponent, for Sede Boqer during the period defined in Table 2. $88 \times 62 \mathrm{~mm}(300 \times 300 \mathrm{DPI})$ 


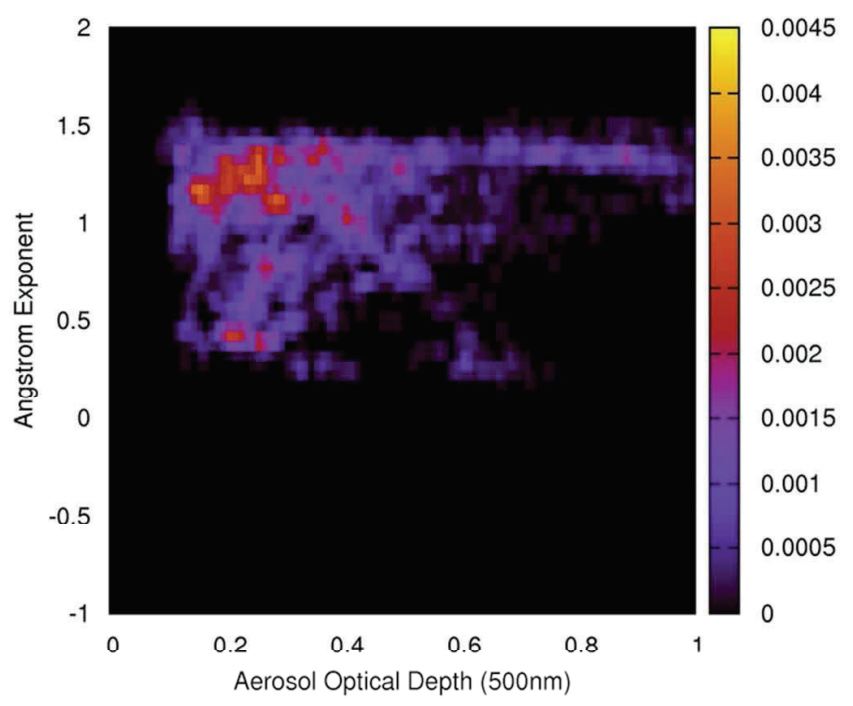
Normalised frequency contour map for aerosol optical depth and Angström Exponent, for Jaipur during the period defined in Table 2 .
$88 \times 62 \mathrm{~mm}(300 \times 300 \mathrm{DPI})$

